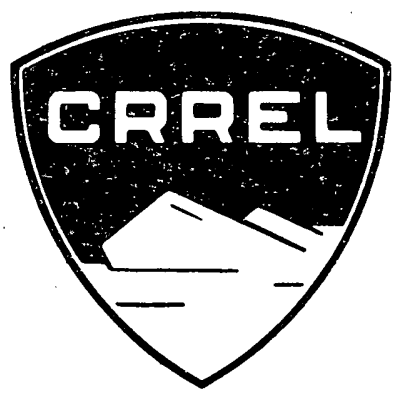

Research Report 219

\title{
THE INTERFACE BETWEEN \\ ICE AND SILICATE SURFACES
}

by

Duwayne M. Anderson.

MARCH 1967

U.S. ARMY MATERIEL COMMAND

COLD REGIONS RESEARCH \& ENGINEERING LABORATORY

HANOVER, NEW HAMPSHIRE.

DA Task IVO $14501 B 52 A 02$

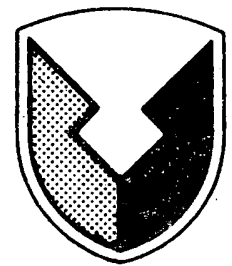


PREFACE

This paper was prepared by Dr. Duwayne M. Anderson, geologist, of the Research Division (Mr. James A. Bender, Chief), U.S. Army Cold Regions Research and Engineering Laboratory.

USA CRREL is an Army Materiel Command laboratory. 
Errata-Research Report 219

p. 5 - The last sentence in paragraph 3 should read:

Regarding the transition between the solid and liquid phases Frank (1958) remarked, 'It may be suggested that if water contains flickering clusters of ice-like material and ice consists of flickering droplets of water-like nature, then the essential difference between the two may be one of connectivity, so that when solid surrounds liquid we have ice and when liquid surrounds solid we have water."

p. 30 - Authors' names in 9th reference on this page should read:

Mooney, R. W. ; Keenan, A. G. ; and Wood, L.A. 
Preface-0. -

Summary -

Nature of silicate surfaces-

Nature of water and aqueous solutions-

Mechanisms of clay-water interaction-

Physical and thermodynamic properties of clay-adsorbed water-...--

The freezing point depression and supercooling

Existence of unfrozen interfacial water-

Spatial distribution of unfrozen water

Nature of the ice phase

Phase relationships

Page

ii

iv

\section{ILLUSTRATIONS}

Figure

1. Schematic illustration of the $1: 1$ and 2:1 types of layer lattice silicates 2

2. Diagram of the $\mathrm{Sp}^{3}$ hybridized orbital model of the water molecule 3

3. Phase diagram for water

4. Resonance structures of water proposed by Frank (1958)

5. Water desorption isotherms of homoionic montmorillonite saturated with various monovalent cations -

6. Water desorption isotherms of homoionic montmorillonite saturated

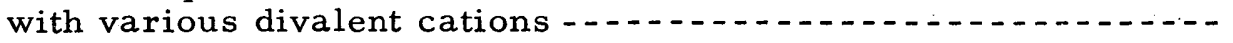

7. The change in $\mathrm{d}(001)$ spacing for several homoionic Wyoming bentonite (montmorillonite) clays during the warming portion of a freeze-thaw cycle - . -

8. Illustration of structural changes due to changes in interlamellar spacing during freezing and thawing

9. Total unfrozen water and unfrozen interlamellar water in sodiumbentonite as a function of temperature-.....

10. The heat capacity of frozen bentonite water mixtures -

11. Schematic phase diagram for water imbibed by montmorillonite showing the effect of clay surfaces on the vapor pressure, the freezing. point and the slope of the solid-liquid equilibria -......

12. Estimate of the latent heat of freezing clay-held water computed from water vapor adsorption on $\mathrm{Na}$-montmorillonite

\section{TABLES}

Table

I. X-ray structural data for ice polymorphs at atmospheric pressure and $-175 \mathrm{C}$

II. X-ray diffraction intensities, $I / I_{002}$ for crystalline water in various frozen clay-water pastes..... 


\section{SUMMARY}

Experiments have been conducted with a particular layer lattice silicate, montmorillonite, in order to study the interaction of water and ice with silicate surfaces. The structural features of this class of silicate minerals are described, and other aspects which have a particular bearing on interfacial phenomena are discussed. Emphasis is placed on the nature of water and aqueous solutions, mechanisms of claywater interaction, physical and thermodynamic properties of clayadsorbed water, freezing point depression and supercooling, the existence of unfrozen interfacial water, spatial distribution of unfrozen water, the nature of the ice phase, and phase relationships. 
THE INTERFACE BETWEEN ICE AND SILICATE SURFACES

by

Duwayne M. Anderson

\section{NATURE OF SILICATE SURFACES}

The bulk of the rock, soil, sand and clay making up the lithosphere is composed of silica or silicate minerals, and the three most abundant elements in the earth's crust are oxygen, silicon and aluminum, in that order. More than 0.9 of the entire volume of the lithosphere is occupied by oxygen; the remaining volume is sufficient to contain all the other constituents. These facts emphasize the importance of the silicates and one of the principal roles of oxygen in the structure of the silicates. In accord with the generalizations of Pauling (1959). the structure of the silicates is determined by the ways in which oxygen atoms coordinate themselves around smaller, more electropositive atoms. In many silicates, the oxygens are more or less close packed with the smaller metallic atoms occupying the interstitial space. Because of their respective radius ratios the coordination number for silicon with oxygen is four; for aluminum it is either four or six. Consequently, the structure of most silicates generally can be described in terms of only two geometrical elements: tetrahedra in which silicon or aluminum exists in tetrahedral coordination with four oxygens and octahedra in which aluminum exists in octahedral coordination with six oxygen atoms. For the most part, atoms of the accessory constituent elements also have radii that permit them to exist in octahedral coordination. The lattices of most silicate minerals are built up of tetrahedra and octahedra having corners and edges in common. When two oxygen atoms of a silica tetrahedron are shared with other tetrahedra, closed rings or infinite chains result; when three are shared, four, six and eight membered rings can be formed; when all four are shared, infinite three-dimensional frameworks result. In this manner, and by similar combinations with octahedral elements, the silicate strutures in all their rich diversity are constructed. They are usually categorized in six groups: Orthosilicates containing discrete $\mathrm{SiO}_{4}^{-4}$ ions; silicates containing $\mathrm{Si}_{2} \mathrm{O}_{7}{ }^{-6}$ ions; silicate ring structures containing $\left(\mathrm{SiO}_{3}\right)_{n^{-2} \mathrm{n}}$ ions; silicate chain complexes (pyroxenes and amphiboles); silicate layer'structures (clay minerals and micas); and three-dimensional silicate framework structures (feldspars and zeolites). The one feature common to all is that, except for fractures, and corners and edges, the surface boundaries of all are the electron clouds of oxygen atoms, so that in virtually all cases when silicates are exposed to water, an interface will be formed between water and the surface-exposed oxygen atoms.

Practically all of the available information on the interaction of water with silicate surfaces has been derived from experiments with the layer lattice silicates and silica gel. The principal points to be made in this paper are derived from experiments with a particular layer lattice silicate, montmorillonite; hence. it is necessary briefly to describe the structural features of this class of silicate minerals. The layer lattice minerals are of two distinct types; the characteristic features of the two types are diagrammatically illustrated in Figure 1. Figure la illustrates a portion of a sheet of linked $\mathrm{SiO}_{4}$ tetrahedra in plan view; three oxygen atoms of each tetrahedron are shared with adjacent groups and the vertices of the tetrahedra all point upwards. Figure $1 \mathrm{~b}$ shows a portion of $a$ sheet of aluminum or magnesium octahedra, also in plan view; here each metallic atom is surrounded by six oxygens and hydroxyls. Part $\mathrm{c}$ is an edge-on view of alternating layers of silicon tetrahedra and aluminum-magnesium octahedra in a ratio of $1: 1$. The kaolinite clays are of this type; they consist of layer upon layer of $1: 1$ units like that shown in c. Part d is an edge-on view of an octahedral layer sandwiched between two silica tetrahedra in a ratio of two tetrahedral to one octahedral layer. The montmorillonite clays and the micas are typical $2: 1$ 

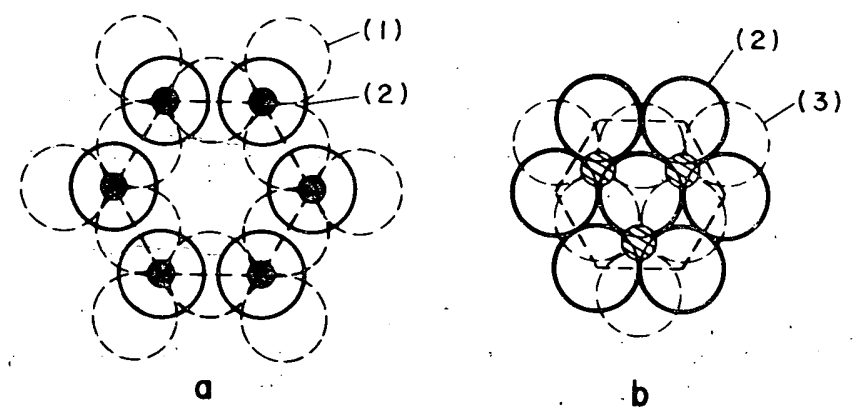

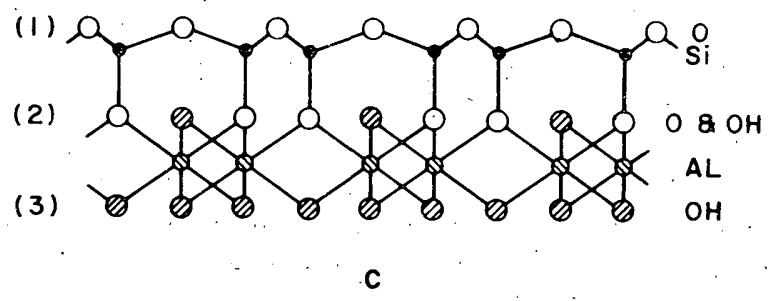

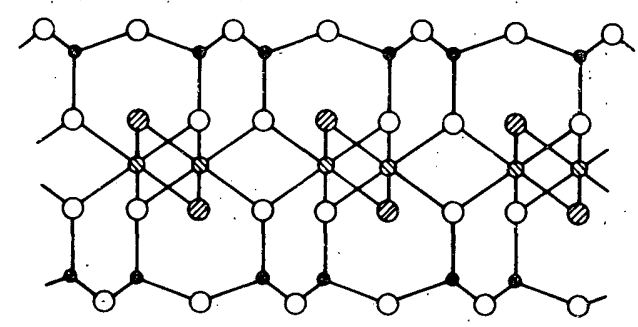

d

Figure 1. Schematic illustration of the $1: 1$ and 2:1 types of layer lattice silicates.

silicate minerals and consist of layer upon layer of the units shown in $d$. In the case of the 2:1 lattice minerals, isomorphous substitutions, commonly aluminum for silicon in the tetrahedral layer and magnesium and ir on for aluminum in the octahedral layer, during formation and subsequent alteration lead to an unbalance of electrical charge. This is commonly compensated for by the presence on the mineral surface of easily exchangeable cations. In montmorillonite clays a delicate balance exists between interlamellar attractive forces and the repulsive forces generated when the crystals are suspended in polar liquids. The repulsive forces often are, sufficient to cause separation of the individual sheets, exposing the entire surface to the liquid. Interlamellar spacings characteristic of the various montmorillonites depend upon the species of exchangeable cation present, the nature of the solvent and whether or not any electrolytes are present. In aqueous suspensions interlamellar spacings as large as several hundred angstroms have been shown to occur. The specific surface area of montmorillonite measured by the adsorption of water vapor or ethylene glycol is about $800 \mathrm{~m}^{2} / \mathrm{g}$ in agreement with that calculated from the dimensions of the unit cell. For comparison, the specific surface areas of typical naturally occurring kaolinites range from 10 to $20 \mathrm{~m}^{2} / \mathrm{g}$ and those of commercial carbon blacks range from about 20 to $100 \mathrm{~m}^{2} / \mathrm{g}$. 


\section{NATURE OF WATER AND AQUEOUS SOLUTIONS}

A comprehensive review of the structure and properties of water is not needed here, there being many excellent ones readily available; however, it is desirable briefly to discuss certain aspects that have a particular bearing on interfacial phenomena.

Oxygen atoms have the electronic configuration $\begin{array}{lllll}1 s^{2} & 2 s^{2} & 2 p_{x^{2}} & 2 p_{y} & 2 p_{z}\end{array}$ therefore, two unpaired p electrons are available for bonding with the unpaired single electrons of two hydrogen atoms. In water, orbital hybridization apparently results in four tetrahedral $\mathrm{Sp}^{3}$ orbitals; two of the orbitals contain the two bonded hydrogen atoms; in the remaining two are the two unbonded "lone pair" electrons. These "lone pair" electrons are capable of interaction with other atomic or ionic species. A diagram illustrating this picture of the water molecule is shown in Figure 2. As shown in Figure 2, the dipole moment of water $\left(1.85 \times 10^{-8}\right.$ esu) can be accounted for by the relative localization of electrons at two apices of a tetrahedron and the positioning of one of the two hydrogen atoms at each of the remaining apices. This representation makes it easy to visualize the possibility of both electrostatic and covalent interactions among adjacent water molecules.

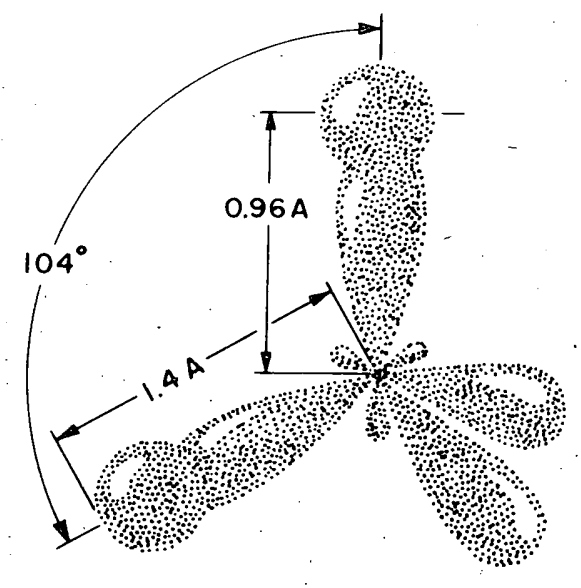

Figure 2. Diagram of the $\mathrm{Sp}^{3}$ hybridized orbital model of the water molecule.

each molecule completely form the four bonds of which it is capable.

Although ice has an abrupt melting point, relatively few of the hydrogen bonds are broken in the transition to the liquid state; consequently, the liquid, to a large degree, retains the openness of the ice lattice. The anomaly is curious but well accepted. Evidence in favor of the view that water molecules in the liquid state are associated and not monomeric is derived from its infrared and Raman spectra, magnetic susceptibility, viscosity, index of refraction, dielectric constant, surface tension, density and the results of X-ray scattering studies. Bernal and Fowler (1933), and Morgan and Warren (1938) have established that near the freezing point the coordination number in the liquid, on the average, is slightly greater than 4 with nearest neighbors about $2.90 \AA$ apart; a marked concentration of next nearest neighbors appears to exist at a distance of $4.8 \AA$. This is indeed remarkably similar to ice in which the four nearest neighbors and the next nearest neighbors are at $2.76 \AA$ and $4.5 \AA$, respectively. 


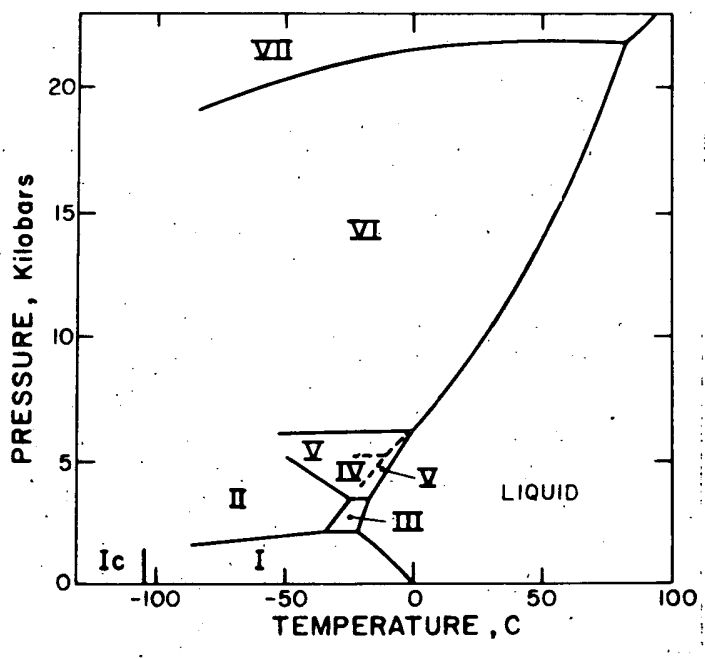

Figure 3. Phase diagram for water. The solid phases (ice polymorphs) are identified by the roman numeral designations assigned by Bridgman, upon whose data the diagram is based. The field of ice IV in relation to ice VI and liquid, shown by dotted lines within the ice $\mathrm{V}$ field, is plotted by analogy to $\mathrm{D}_{2} \mathrm{O}$ ice, for which the field was actually measured; ice IV is everywhere unstable relative to ice V. Ice Ic ("cubic ice") is shown schematically below the temperature of about $-105 \mathrm{C}$, below which it forms by vapor condensation and above which it inverts to ice I; it is not known to have a field of actual stability. (after Kamb, 1965)

Table I. X-ray structural data for ice polymorphs at atmospheric pressure and -175C. (after Kamb, 1965)

\begin{tabular}{|c|c|c|c|c|c|}
\hline Ice & $\begin{array}{l}\text { Density } \\
\left(\mathrm{g} \mathrm{cm}^{-3}\right) \\
\end{array}$ & $\begin{array}{l}\text { Crystal } \\
\text { system } \\
\end{array}$ & $\begin{array}{l}\text { Space } \\
\text { group } \\
\end{array}$ & $\begin{array}{l}\text { Cell dimen- } \\
\text { sions }(\AA)\end{array}$ & Z* \\
\hline I & .0 .92 & Hexagonal & $\mathrm{P}_{\mathrm{a}} / \mathrm{mmc}$ & a 4.48, c 7.31 & 4 \\
\hline Ic & 0.92 & Cubic & $\mathrm{Fd} 3 \mathrm{~m}$ & a6.35 & 8 \\
\hline II & 1.17 & Rhombohedral & $\mathrm{R} \overline{3}$ & a7.78, a $113.1^{\circ}$ & 12 \\
\hline IIII & 1.14 & Tetragonal & $\mathrm{P} 4_{1} 2_{1} 2$ & a6.79, c6.79 & 12 \\
\hline IV & 1.28 & & & & \\
\hline $\mathrm{V}$ & 1.23 & Monoclinic. & $\mathrm{A} 2 / \mathrm{a}$ & $\begin{array}{l}\text { a9. } 22, \text { b7. } 54 \\
\text { c10.35, } \uparrow \beta 109.2^{\circ}\end{array}$ & 28 \\
\hline VI & 1.31 & Tetragonal & $\mathrm{P}_{2} / \mathrm{nmc}$ & a6. 27, c 5.79 & 10 \\
\hline VII & 1. 50 & Cubic & $\mathrm{Pn} 3 \mathrm{~m}$ & a3. 41 & 2 \\
\hline
\end{tabular}

* Number of molecules in the unit cell.

$\dagger$ ¡amb's value was inadvertently printed 1035.

The structure of the liquid is less well known than that of the solid, but is receiving much attention. Progress is being made in the construction of models that are consistent with the physical and thermodynamic properties of water. Many models have been proposed, but none is yet fully acceptable. The various models proposed are typified by:

1. The quartz-like, broken-down ice structure of Bernal and Fowler (1933) and Morgan and Warren (1938). (1948).

2. The monomer, dimer, tetramer and octamer mixture model of Eucken

3. The flickering cluster model of Frank and Wen (1957).

4. The clathrate model of Pauling (1959).

5. The fluidized vacancy theory of Eyring and his colleagues (1963). 
The Bernal and Fowler and Morgan and Warren model has been and possibly still is the most widely known and accepted of the five. The most attractive features of this model are extensive hydrogen-bonded regions with a gradual reduction in size of these hydrogen-bonded domains with temperature. The model is criticized most often because a quartz-like structure requires a considerable strain in the hydrogen bonds and because the model is unattractively rigid.

The Eucken mixture model is, in a sense, the ultimate elaboration of earlier proposals postulating the existence of polymeric species in varying proportions. By postulating the existence of monomers, dimers, tetramers and octamers and by giving a numerical value to the equilibrium constant for the thre $\epsilon$ independent equilibria among them, Eucken could account for the PVT behavior of water up beyond the boiling point and at high pressures, but this model has not been widely accepted. Probably the main objection has been that the model and its assumptions are too simple to be taken literally and the fit of calculated to observed data, while impressive, is somewhat rough (Frank, 1963). It has been noted that this model is in contradiction with self-diffusion and dielectric-relaxation measurements, which suggest only one diffusing species and only one relaxation mechanism, but the existence in the liquid of some or all of the postulated species has by no means been ruled out.

The flickering cluster concept of Frank and Wen provides a most useful model; it is physically realistic; it contains an explanation of the various observed characteristics of water including the phenomenon of maximum density, the dependence of viscosity on temperature and pressure, relaxation times, etc.; and it is compatible with statistical methods. In this approach, the hydrogen bond in water is recognized as being partially covalent in character so that large deviations from linearity in the $\mathrm{O}-\mathrm{H}$... O directions are not possible. They propose that the bond can be described in terms of the three resonance structures of Figure 4 . Because structure III produces a separation of electrical charge, molecules a and $b$ can. form additional hydrogen bonds more easily than was possible before; consequently, Frank and Wen suggest that bond formation is a cooperative phenomenon and that bonds are not formed singly but several at a time so that at any instant short-lived clusters of extensively hydrogen bonded regions will be found surrounded by nonbonded molecules. The organization and destruction of these "flickering clusters" is determined by fluctuations in the localized energy distribution. Regarding the transition between the solid and liquid phases Frank (1958) remarked, "It may be suggested that if water contains flickering droplets of water-like nature, then the essential difference between the two may be one of connectivity, so that when solid surrounds liquid we have ice and when liquid surrounds solid we have water."

Pauling's clathrate model visualizes a water network so arranged that it forms cages containing cavities 5 to $7 \AA$ in diameter that contain unbonded water molecules. The structural background required for an examination of this model recently was given by Jeffrey (1963) who showed that it is a tenable idea from a geometrical point of view. Frank and Quist (1961) have shown that the model can account satisfactorily for the maximum density phenomenon and the compressibil: ity of water. Why some molecules should be completely bonded into cage structures and why some should not is a troublesome question but not so troublesome as to vitiate the model. Nemethy and Scheraga (1961) have pointed out that the clathrate model is unable to give a good explanation of solution thermodynamics for non-polar molecules and seems unrealistically rigid for a fluid of low viscosity. They conclude that the occurrence of clathrate-like structures in the pure liquid may be infrequent but the possibility of occurrence cannot be denied on the basis of present knowledge.

Eyring and his colleagues are developing the "significant structures"! theory of liquids. Their model pictures the liquid as a quasi-solid containing fluidized vacancy defects of molecular size. The vacancies migrate about from 
$\mathbf{I}$

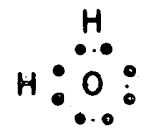

a.

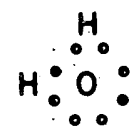

a.

II

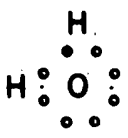

b.

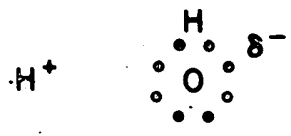

b.

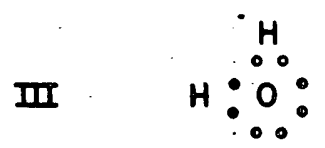

C.

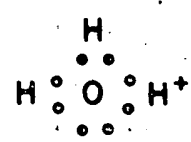

a.

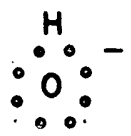

b.

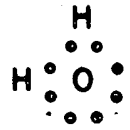

d.

Figure 4. Resonance structures of water proposed by Frank (1958).

site to site as they are successively filled by a neighboring molecule. The number of vacancies present is determined by energy and entropy considerations; as the temperature is increased past the melting point, the number is thought to abruptly increase from virtually zero to about $10 \%$ of the number of molecules present, corresponding to the normal $10 \%$ increase in volume experienced by most liquids. This model has proven to be highly successful for the liquid noble gases, a number of diatomic liquids, some organic liquids and molten metals. It has even been said to be promising in the case of binary mixtures (Eyring and Marchi, 1963). Although the structure of liquid water is recognized as a special problem, Marchi and Eyring (1964) believe that it can be fruitfully described in terms of the fluidized vacancy model. They would regard the liquid as being composed primarily of two species: structured clusters of molecules tetrahedrally bonded and therefore not free to rotate and unbonded molecules that do freely rotate. The ratio of the two species is regarded as governed by an equilibrium constant and as the temperature is increased, more and more molecules are thought to rupture their bonds, thus gaining rotational freedom. The process of melting is thought to correspond to an abrupt change to dense, but still tetrahedrally bonded, clusters of molecules roughly $20 \%$ smaller in molar volume than the solid. At the same time "fluidized vacancies" are introduced in numbers sufficient to cause a $10 \%$ increase in volume. The net result is the $10 \%$ decrease in volume observed on melting. Actually, two types of voids are visualized: one type results from the relatively bulky way in which the clusters are thought to pack; some or all of these intexstitial voids contain rotating monomers. The other type is of molecular size and is found migrating about through the hydrogen-bonded clusters; it is these voids that are referred to as fluidized vacancies. With an increase in temperature more water molecules break loose from the clusters and move into the interstitial voids, tending to decrease the molar volume, but the temperature increase also causes the appearance of more fluidized vacancies, tending to increase the molar volume: Thus, the density anomaly is explained by supposing that below $4 \mathrm{C}$ the break-down of hydrogen-bonded networks and the filling of 
interstitial sites predominates so that there is a net decrease in volume. Above $4 \mathrm{C}$ the introduction of vacancies is predominant and water behaves as a normal liquid. On the basis of this model, Jhon et al. (1966) have formulated the partition function and computed thermodynamic properties of the liquid in moderately good agreement with observed values.

Another recent development of the two-state mixture approach is the model of Davis and Litovitz (1965). They propose a mixture of an interconnected, icelike ring structure and a more close-packed body-centered cubic structure. This theory, like Eucken's, emphasizes geometrical details and satisfactorily explains many properties of the liquid. However, to explain the calculated large temperature dependence of the relaxational portion of the specific heat it was necessary to postulate the possible existence of a third species in the mixture.

In aqueous solutions the presence of dissolved ionic and molecular substances exerts an influence on the nature of the water structure. Interactions through covalent or hydrogen bonds and electrostatic interactions are expected to result in a tendency towards a certain geometrical order in the vicinity of the individual molecules and ions. The effect could be to disrupt the normal water structure on the one hand or to enhance its development on the other, depending upon the species involved. It has been noted that cesium and iodine ions appear to disrupt the normal water structure, whereas lithium and fluorine ions appear to promote the development of hydrogen-bonded network's. It is widely believed, on the basis of electrochemical data, that the ions in aqueous solutions cannot move independently of the solvent but carry with them a hydration hull. This makes it easy to explain the phenomenon of electroosmosis and why the lithium ion has the lowest mobility in water of the monovalent alkali-metal cations, lithium, sodium and potassium, even though it is the smallest ion of the three. Gurney (1953) has called attention to the difficulty, especially for singly charged ions, of visualizing the formation of a stable, hydrated ion with a spherical boundary, and he has maintained that the most useful concept would recognize that ions or molecules can never be in contact with fewer than three or four water molecules, which in turn are in contact with others, so that it is the total interaction with all the solvent that is meant when one speaks of ion solvation. Nevertheless, as Frank and Wen (1957) point out, most investigators agree that in aqueous solutions. containing small ions, the nearest-neighbor water molecules must be essentially immobilized by ion-dipole interaction. However, they argue that the ions also musi exert an influence on the equilibrium between the various species of hydrogen-bonded clusters and non-bonded monomers present. Although correlations between various experimentally observed properties of ionic solutions and the structure-making or structure-breaking influence of various ions have been possible, a successful theory of ionic solutions along these lines has yet to appear. Probably the only justifiable conclusion at this time is that most ions appear to exert a disrupting influence on the water structure but there are exceptions, notably lithium and fluorine. Moreover, it has been discovered that many non-polar solutes also exert a structure-producing influence, notably the rare gases and a rather large number of hydrocarbon gases. In some instances, as mentioned earlier (Jeffrey, 1963), the geometrical configurations of the induced structures have been determined.

\section{MECHANISMS OF CLAY -WATER INTERACTION}

Clay-water interactions have received much attention due no doubt to the industrial, engineering and agricultural importance of clays and clay-water mixtures. In the study of interfacial phenomena, it frequently is desirable to utilize samples possessing large interfacial areas; consequently, the clay minerals often have been selected for investigation in preference to other silicate minerals. In addition, since each investigation tends to build upon and exploit 
preceding work and one experiment leads to another, the clay minerals are now. well characterized and understood; hence, they seem to be increasingly appropriate subjects for basic investigations of interfacial phenomena.

The experimental and theoretical evidence pertaining to clay-water interactions has been examined in several recent reviews (Rosenquist, 1959; Low, 1961; Martin, 1962; Graham, 1964). Fundamentally, there are three factors to consider; direct interaction of water with the mineral lattice, ion hydration, and London-van der Waal's forces of attraction. All are known to be important factors although there is still disagreement on their relative importance. It has been observed that the clay mineral surfaces consist of network arrangements of oxygen atoms or hydroxyl groups whose geometrical array bears a striking resemblance to that existing among water molecules in ice and that the two structures can be matched with only a little rearrangement of bond angles and lengths. On this basis it was early postulated that clay-water interaction might result in an interface bound to the clay lattice by hydrogen bonds. Briefly, the argument justifying such a postulate is that, because of isomorphous substitution of cations of lower valency for those of higher valency, the clay lattice contains an overabundance of electrons. Although over-all electrical neutrality is preserved by the surface adsorption of exchangeable cations the excess of electrons in the lattice facilitates the distortion of the lone pair electrons in the lattice oxygens. Assuming that these electrons can be distorted by a proton, then hydrogen bonds to the clay surface and throughout the interface can form in the cooperative manner of Frank (1958), and the existence of a hydrogen-bonded clay-water interface certainly is plausible (Low, 1961). Because of the propagation of cooperative effects, the hydrogen-bonded interface could be many molecular layers thick. It would possess a distinct boundary with the mineral surface on one side but would extend outward with less and less coherence, finally merging with the bulk water structure on the other.

The presence of exchangeable cations (for monovalent cations on montmorillonite they are spaced on the average about $10 \AA$ apart) not only provides a second mechanism of clay hydration but must be accounted for in any structural concept of clay-adsorbed water such as that just mentioned. The water vapor desorption isotherms (adsorption data are less reproducible) for va rious homoionic montmorillonites shown in Figures 5 and 6 are revealing in this respect (Mooney, Keenan and Wood, 1952). The fact that the clays whose exchange capacities are saturated with the divalent cations and with hydrogen, sodium and lithium take up several times as much water at the lower relative pressures as do the potassium-. rubidium-and cesium-saturated clays shows that the exchangeable ions certainly are involved initially in water uptake. Although the often repeated assertion that the ions hydrate before hydration of the surface is questionable, it is clear that with the possible exception of potassium, rubidium and cesium, the exchangeable cations combine to exert a powerful initial attraction for water. Even at higher water contents there are important differences in the influences of the different 1ons. The effects are of two kinds: points of inflection that come at different water contents and continually changing ratios, one ion to another, of water adsorbed at various relative pressures. Thus it can be seen that ion hydration is not only effective initially in attracting water to the clay surface but it also plays a significant role during subsequent states of wetting. Even at very high water contents, ion hydration effects must be expected because, depending upon the cations present, many of the hydrated lons can dissociate from the surface, and at some distance from the surface the ions may be regarded as being in aqueous solution; hence, their effect will be to lower the thermodynamic activity of water in the interfacial region. In addition to the structural implications, this means that the dissociated ions will produce osmotic effects and thus affect the freesing and melting points of the interfacial water.

It has been shown by $X$-ray diffraction that at the lower water contents many of the $2: 1$ clay minerals form a series of more or less distinct hydrates (Mooney et a1. 1952). This is most obvious in the case of vermiculite and it has been. 


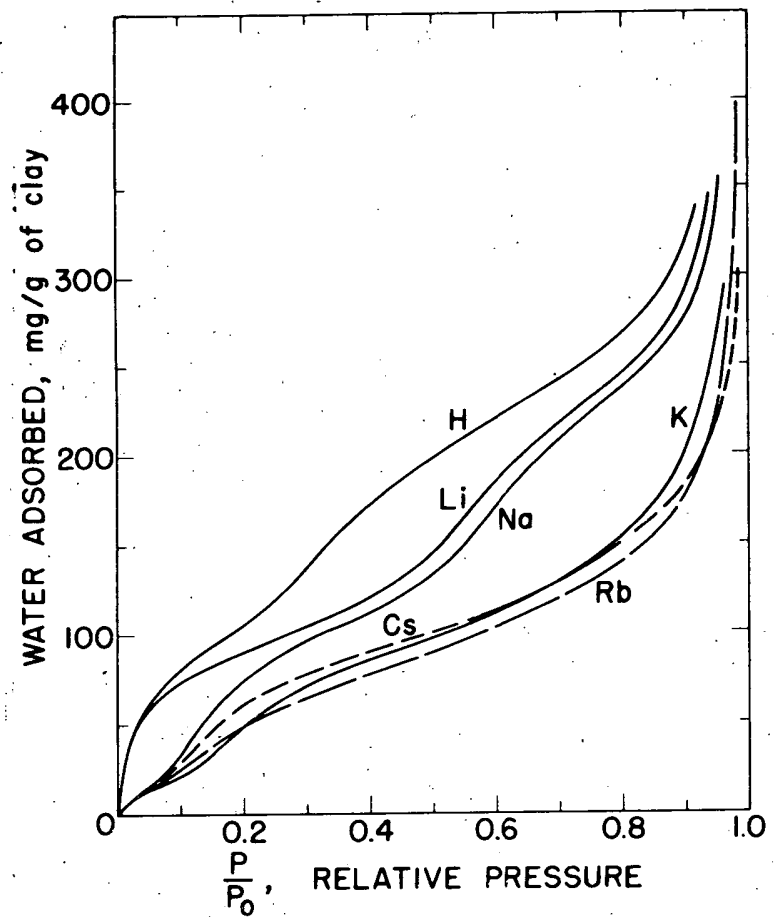

Figure 5. Water desorption isotherms of homoionic montmorillonite saturated with various monovalent cations.

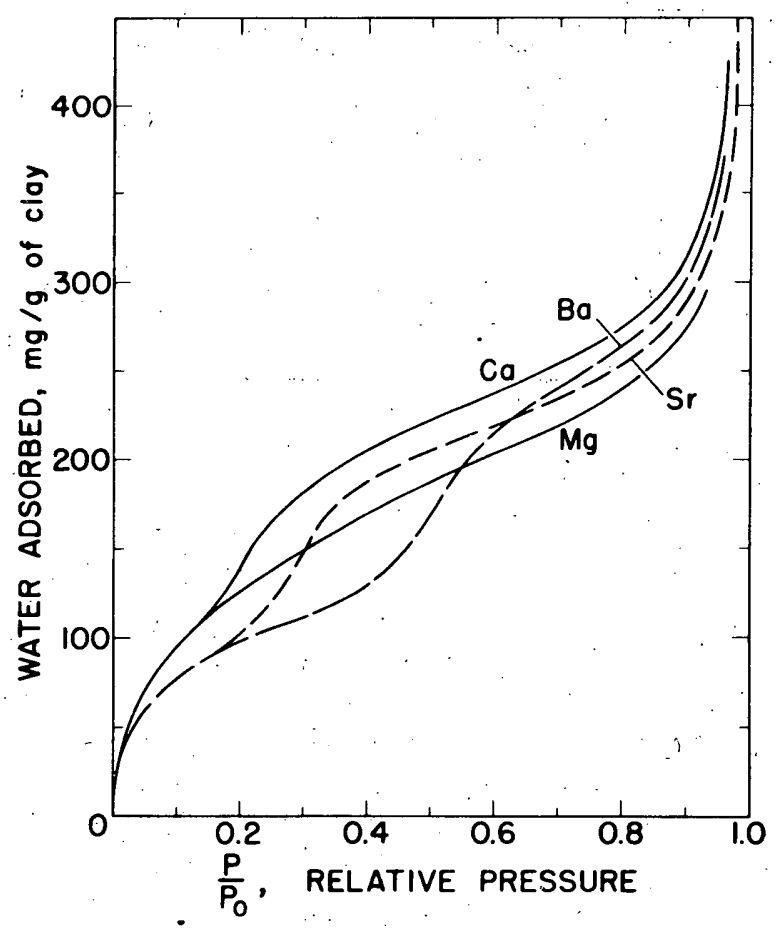

Figure 6. Water desorption isotherms of homoionic montmorillonite saturated with various divalent cations.

possible by X-ray diffraction to deduce the structural details of the two-layer hydrate (Mathieson and Walker, 1954; Mathieson, 1958). In this case the structure consists of water molecules arranged in groups of six around each possible cation site. As the water contents and temperatures were varied, other geometrical arrangements were observed. Similarly, a dependence of interfacial molecular structure on water content, temperature and ionic species is to be expected on all silicate surfaces. Moreover, it is probable that hydroxy-iron and -aluminum complexes and adsorbed oxygen, nitrogen or other gases play significant roles in the structure of interfacial water. Evidence supporting this idea recently was reported by Migal and Russu (1964). They found that adsorption of the vapors of $\mathrm{Me} \mathrm{OH}$, Et OH, $\mathrm{C}_{6} \mathrm{H}_{6}, \mathrm{CH} \mathrm{Cl} \mathrm{C}_{3}, \mathrm{Me}_{2} \mathrm{CO}$ and $\mathrm{Et} \mathrm{O}_{2}$. by charcoal and silica gel was increased by the addition of small quantities of air although the effect was noticeable only during formation of the first monolayer. Thus any comprehensive structural description of the interface must necessarily be complex.

Interactions of the well known but poorly understood London-van der Waal's type arise from the non-directional London dispersion forces that can be induced when water molecules approach the surface with low velocities. Attraction results from the cooperative in-phase resonance of the electronic clouds surrounding the oxygen nuclei. The effect of fluctuations in the electron clouds is to create at any instant a series of dipole-dipole attractions. The interaction vectors are constantly shifting but the net result of the interaction is always an attractive force. Finally, the familiar ion-dipole, dipole-dipole, etc. van der Waal's interactions also contribute to the total interaction.

\section{PHYSICAI, AND THERMODYNAMIC PROPER TIES OF CLAY-ADSORBED WATER}

Interactions at the interface between water and silicate surfaces result in changes in the properties of the interfacial water. For example, the relative 
immobilization of the water molecules must result in a decrease in the dielectric constant and a decrease in the fluidity of the interfacial water. Any structural change in the water due to the interfacial interactions would probably result in changes in the water density, specific heat, etc.

In accordance with expectation, both the real and imaginary parts of the complex dielectric constant of clay-water mixtures vary with water content in a manner consistent with the concept of partially immobilized, surface-bound water, but unambiguous conclusions are not possible for the data may be interpreted in more than one way. Nuclear magnetic resonance data (Wu, 1964) also indicate marked interaction between the clay surface and the first layer of interfacial water indicating a substantial reduction in the mobility of the water. Surface interaction with the second layer is clearly much less intense than with the first, but both the dielectric and NMR data provide evidence of substantial interaction in water films many molecular diameters thick. Although initially adsorbed water molecules are under constraints that reduce their freedom of motion, thermal agitation is still sufficient to permit complete exchange with $D_{2} O$, indicating that this water retains the mobility of a fluid to a large degree. Similar conclusions have resulted from NMR studies of water adsorbed by silica gel (Zimmerman and Lasater, 3 1958).

Many measurements of the density of clay-adsorbed water have been attempted but with conflicting results. The methods commonly employed require assumptions that prevent unambiguous interpretations of the data. The only applicable, presently available density data uncomplicated by troublesome assumptions are those of Anderson and Low (1958). Their data show that the density (computed from partial specific volumes) of the surface-held water in montmorillonite clay is about $3 \%$ less than that of pure bulk water at the same temperature. The density difference becomes smaller at greater and greater distances from the surface but is still detectable at $50 \AA$.

Numerous permeability and diffusion studies have been undertaken to determine the effect of surface interaction on the fluidity of clay adsorbed water. Almost without exception the data have indicated that the surface influenced water is somewhat more viscous and has an activation energy for movement that is slightly higher than that of water in bulk. In reviewing this topic, Martin (1962) argues that it is possible to account for the experimental observations in ways other than a surface-induced water structure of reduced fluidity. He mentions the possibility of clay particle reorientation, of clay decomposition releasing iron and aluminum ions that then form complexes during the experiments, and the temperature dependence of the permeability and entropy as being of sufficient importance to weaken the conclusions derived from measurements of hydraulic permeability and diffusion coefficients. Nevertheless, the viscosities and activation energies deduced from such measurements are consistent with expectation and with other evidence. Moreover, as Low has pointed out (1961), the existence of a threshold value of the hydraulic gradient below which flow does not occur in clay-water mixtures, confirmed by several investigators, most recently by Miller and Low (1963), is an impressive indication of the elevated viscosity of the interfacial water.

The question of the distances at which the influence of silicate surfaces on the water structure are evident is an important one; all the reviews pertaining to clay-water interaction cited earlier consider it. Apparently the question is still debatable although, to the writer, the weight of the evidence is clearly indicative of a significant influence extending at least $50 \AA$ outward from the surface. Some recent evidence to this effect, not available to earlier reviewers, is the observation that in thixotropic clay-water gels a reversible volume change accompanies the sol-gel-sol transition (Anderson et al., 1963). A time-dependent volume increase occurred during gelation. The phenomenon seems to be best explained by assuming the progressive development during gelation of a surface-induced 
water structure that can be broken down by agitation and disruption of the gel. If this explanation is accepted, it indicates that the induced water structure is less dense than that of pure, bulk water, in accord with the density data cited above. The validity of this interpretation was corroborated by the results of Hiller (1964) and Lange (1965), who utilized it to design their high pressure studies of the viscosity and electrical conduction of clay-water suspensions:

Regarding the system as containing two phases in equilibrium, the solid phase and an adsorbed phase, relationships between the Gibb's free energy, enthalpy, entropy and other thermodynamic functions can be derived. For instance, the temperature dependence of the vapor pressure of the adsorbed water, at constant surface coverage, can be obtained from adsorption isotherms of the type illus trated in Figures 5 and 6 . Then from the appropriate form of the ClausiusClapeyron equation,

$$
\left(\frac{\partial \ln p}{\partial \mathrm{T}}\right)=\frac{\Delta \overline{\mathrm{H}}}{\mathrm{R} \mathrm{T}^{2}}
$$

the partial molar enthalpy of the adsorbed phase can be computed. In eq $1 \cdot \Delta \bar{H}$ is the isosteric heat of adsorption and corresponds to the difference in partial molar enthalpy between water vapor and the adsorbed phase at the temperature $T$, and $\mathrm{R}$ is the universal gas constant. Isosteric heats of adsorption determined in this way clearly show that energetically the first water monolayer is vastly different from the pure bulk liquid; for subsequent layers, this difference is very much less, however. Prominent points of inflection in a graph of $\Delta \overline{\mathrm{H}}$ occur at water contents corresponding approximately to one and two interlamellar water layers. The partial molar enthalpy of the surface-held water also has been determined directly by calorimetric measurements with similar results.

The partial molar free energy of the adsorbed water is easily obtained from the adsorption isotherms since it is given, relative to the reference state, $F^{\circ}$, by

$$
\bar{F}=F^{\circ}+R T \ln p / p^{\circ}
$$

assuming that the vapor pressures may be substituted for fugacity. In eq $2, p$ is the equilibrium water vapor pressure of the adsorbed phase and $p^{\circ}$ is the vapor pressure of water in the reference state, usually the pure liquid at the temperature, $T$. The partial molar entropy has been regarded as the most interesting thermodynamic function because it carries connotations of order-disorder. It can be derived from the temperature derivative of the partial molar free energy relative to the entropy of water in the standard state, $S^{\circ}$. The equation is:

$$
\bar{S}=S^{0}-\frac{\partial}{\partial T}\left[R T \ln \mathrm{p} / \mathrm{p}^{\circ}\right]
$$

It follows from eq 1 and 3 that

$$
\bar{S}=S^{\circ}-\frac{\Delta \bar{H}}{T}-R \ln p / p^{\circ}
$$

The partial molar entropy of clay-adsorbed water, $\bar{S}$, has been computed by several investigators. It has been determined from adsorption isotherms alone and also in conjunction with calorimetric measurements. Discussions of the results are given in the reviews cited earlier. Almost without exception, it has been found that the partial molar entropy of the interfacial water is lower than that of the pure bulk liquid, and this has been interpreted to mean that the interfacial water is "less random" in its structural arrangement. The curves resulting from plots of the partial molar entropy versus water content or surface coverage 
almost invariably exhibit interesting points of inflection that can be correlated with ion hydration, completion of a monolayer, onset of lattice expansion, etc.

It cannot be overstressed, however, that caution should be exercised in attempting geometrical or mechanistic interpretations of thermodynamic data. Such interpretations can be accepted only after they have been proven by independent methods. Here it is well to recall from the partition functions in the quantumstatistical expression of entropy that a decrease in entropy can result from a decrease in any of several degrees of kinetic freedom and that a dependence upon structural geometry is only incidently implied in the concept of entropy. In addition, the use of partial molar entropies in the elucidation of surface interactions, geometrical configurations, etc. has been severely questioned on the grounds that, because hydration and dissociation of the exchangeable cations and other perturbations of the solid part of the interface surely occur, a satisfactory definition of the partial molar entropy for either component is not possible. Consequently, it is held that valid interpretations of partial molar entropy data rest entirely on proven correlations and other extra-thermodynamic data. After Hill (1950), Martin (1962) has advocated the use of a uniquely defined integral entropy in dis cussions of the configuration of the interfacial molecular species at low water contents. The integral entropy so defined can be regarded as a property of the adsorbed water but, unless the surface properties of the solid phase are reproducible and do not change or degrade with time, interpretations of the intergral entropy are also questionable. Martin found positive integral entropies for the water initially adsorbed by kaolinite, from which he concluded that the initially adsorbed water molecules were more random in configuration than is the case in the bulk liquid. He determined the partial molar entropy of the adsorbed water on the same sample, and, except for the very first water molecules adsorbed, found negative values as usual. Kolaian and Low (1960) determined the partial molar free energies, enthalpies, and entropies of thixotropic montmorillonitewater systems at very high water contents; all were found to be measurably less in the'gel state than in pure bulk water. From this it was concluded that the effects of the silicate surface and the exchangeable ions were manifest throughout the entire system. Probably the only valid conclusion possible from entropy data at the present time is that, in agreement with other thermodynamic data, the most intense interaction occurs between the surface and the first monolayer and that the intensity of interaction falls off rapidly with distance from the surface. Configurational models of the interface based upon thermodynamic data alone cannot be constructed and the thermodynamic data cannot be used to prove the existence of any particular model, although they do rule out some impossible models.

Although the partial specific heats of adsorbed phases are of considerable importance because they depend intimately upon the nature of the interface formed and interaction with the surface, determinations of this quantity for silicate surface-water interfaces are few in number. As pointed out in a recent review (Young and Crowell, 1962) the heat capacity curves for water on silica gel surfaces show maxima at temperatures below the normal bulk melting point; these were interpreted as corresponding to the melting of the adsorbed films. Similaxly, Oster and Low (1964) attributed the high partial specific heat (1.0 to 1.1 cal/g-deg) of the interfacial water in montmorillonite-water mixtures as being due to a partial melting of a "quasi-crystalline" water structure partially hydrogen-bonded to the silicate surface.

The preceding paragraphs are an attempt to highlight some of the most pertinent facts bearing on the properties of water next to silicate surfaces. In view of the complexities involved it is somewhat remarkable that, even though few of the experimental results are uncomplicated by troublesome assumptions and much of the evidence is circumstantial, it nevertheless has been possible to deduce the outlines of a reasonably reliable visualization of the nature and condition of the interfacial water. Without specifying geometrical details, the 
"flickering cluster" concept of more or less extensive regions of cooperative, hydrogen bonding in normal water is a useful one and may be accepted for the present. On the time scale of molecular vibration, these clusters are identifiable but their lifetime before breaking up and reforming is quite brief $\left(10^{-10} \mathrm{sec}\right.$ or less), and is governed by local shifts in concentration of thermal energy. At the interface with silicate surfaces the relatively intense interaction in the first, and possibly the second, water monolayer results in the loss of large portions of the translational, and possibly rotational, degrees of freedom among individual water molecules. In addition to interaction with surface-held ions and impurities, interaction with the surface oxygens through the hydrogen bond must also play a significant role. It is probable that the net result of these effects is to increase the coherence and extent of hydrogen-bonding in the interfacial liquid and to lengthen, perhaps considerably, the lifetime of individual hydrogen-bonded domains. In certain situations, as in the interlamellar space of hydrated vermiculite, regular, hydrogen-bonded networks exist, but more commonly thermal motions and the competing influence of the electrical fields of the ions present prevent the formation of rigid structures. The influence of the surface must diminish with distance outward so that the stabilizing effects that tend to enhance the development of structure in the interfacial water also diminish. However, since the normal liquid is highly structured and, moreover, possesses a structure that is delicately balanced and sensitive to slight environmental perturbations, the influence of surfaces no doubt is effective in enhancing the development of structure, in the interfacial water far beyond the first monolayer. At lower temperatures the induced structural effects must be more and more extensive and the water structures more and more coherent. Many geometrical configurations are possible and, since the degree of hydration and dissociation from the surfaces is different in general for every surface and for every ionic or molecular species, the number of different structural configurations actually existing at one time or another must be enormous.

Interaction at the air-ice interface is thought to result in a liquid-like interfacial layer on ice and perturbations in the normal water structure existing at the interface with air or ice surely must occur also. Little is known about these perturbations but it is probable that interactions at the ice-water interface are not very severe so that they are of minor consequence compared with interfacial interactions at the water-silicate surface interface. With this understanding, tentative though it may be, let us proceed to examine the question of thickness, spatial distribution, and properties of the interface separating ice from silicate surfaces.

\section{THE FREEZING POINT DEPRESSION AND SUPERCOOLING}

The pioneering work of Bouyoucos (1916) laid the foundation for modern investigation of freezing phenomena in earth materials. He studied the freezing point depression and the supercooling of soil water. In addition to identifying the governing factors, and providing phenomenological characterizations, he correlated supercooling and the freezing point depression to "physically adsorbed or loosely chemically combined" water, water "not free to act as a solvent." $\mathrm{He}$ demonstrated that frozen soils contain significant amounts of water that apparently does not change phase during freezing and thawing of a bulk specimen and correlated the amount of soil water remaining unfrozen at $-4 \mathrm{C}$ with the wilting coefficient of the soil. Since the wilting coefficient of soils was known to be related to the specific surface area of the soil, by implication he connected the unfrozen water with the interfacial interaction between the surfaces of the soil minerals and soil water. He also expressed the belief that pore geometry and the manner in which freezing proceeded were important governing factors.

Since Bouyoucos' early work the freezing and thawing of water in porous soils and clays has been the subject of many investigations.: As a result, the freezing 
point depression, the tendency of soils to supercool before freezing, the existence of "unfrozen water," and the effect of dust particles in ice nucleation are familiar phenomena; nevertheless, these phenomena to a large degree remain unexplained and imperfectly understood.

Two equations are commonly used to explain the freezing point lowering due to interaction between a porous body and its imbibed water. The Gibbs-Thomson equation (Dufour and Defay, 1963),

$$
T=T_{0} \exp \left(\frac{2 \sigma V}{r \Delta \bar{H}_{f}}\right)
$$

gives the equilibrium temperature of freezing $\mathrm{T}$, in terms of the freezing point of pure water $\mathrm{T}_{\mathrm{O}}$, the interfacial tension $\sigma$, the specific volume of ice $\mathrm{V}$, the latent heat of freezing $\Delta \bar{H}_{f}$, and the radius of curvature of a spherical body of ice $r$. Since the dimensions of the pore space, determined by the constraints of surrounding mineral surfaces, fix the maximum size of a growing ice body and, in a sense, determine $r$ in eq 5 , it is seen that the Gibbs-Thomson equation explains the freezing point depression in terms. of the pore geometry of a porous substance. Equation 5 is an approximation valid only for small freezing point depressions; moreover, in addition to the assumption of a spherical interface it is assumed that the heat of phase change is independent of interfacial curvature and the values of both $\Delta \bar{H}_{f}$ and $V$ are averaged over the temperature difference $\left(T_{O}-T\right)$ to account for their dependence on temperature. Particularly severe limitations on the application of eq 5 to phase equilibria in porous bodies or capillaries result from the requirement that the pressure existing in the liquid phase must be taken as constant. This requirement cannot be satisfied in partially filled capillaries or partially saturated porous bodies, where the configuration of the air-water interface determines the. pore water pressure, nor can it be regarded as satisfied in the presence of an adsorption force field. Consequently, although it is of intrinsic interest, the Gibbs-Thomson equation has proven to be of limited value.

Another equation in common use, actually a form from which eq 5 may be derived, relates the activity. of interfacial and pore water to its equilibrium freezing point depression. It is

$$
\ln \frac{a}{a^{\circ}}=\frac{\Delta \bar{H}_{f}}{R\left(\frac{1}{T}-\frac{1}{T^{\circ}}\right)}
$$

in which $a$ and $a^{\circ}$ are the activities of the interfacial or pore water and of pure water under a flat air water interface, respectively; $\Delta \overline{\mathrm{H}}_{f}$ is the latent heat of freezing averaged over the temperature interval involved; $R$ is the universal gas constant; $T$ and $T^{\circ}$ are the freezing temperatures of the interfacial or pore water and of pure bulk water, respectively. As in the case of the Gibbs-Thomson equation, the derivation of eq 6 requires the assumption that the pressure on the two phases is constant which, as just mentioned, cannot be true in most cases of interest: Because of this and other questionable assumptions, in spite of its long history of useful application in estimating the energy status of soil water, eq 6 cannot ultimately be relied upon either. The simplifications in the general thermodynamic equations required to yield eq 5 and 6 are not the only possibilities, but incenives justifying alternative treatments have been slow to appear; however it would appear that further work is certainly warranted.

The phenomenon of supercooling, involving as it does the existence of metastable states, is at least an order of magnitude more complex than is the problem of the freezing point depression and, except for certain pure substances, it is even less well understood. Although many papers on this topic are to be found and.

several descriptive observations might be considered, this topic is not central to the present theme and therefore will not be considered further. 


\section{EXISTENCE OF UNFROZEN INTERFACIAL WATER}

Bouyoucos established the existence of "unfrozen water" in frozen earth by confining moist soil in a dilatometer filled with a liquid immiscible with water. After carefully supercooling the sample under controlled conditions, he initiated freezing by sharply striking the sample container and observed the expansion accompanying freezing by the rise in level of the immiscible liquid. The expansion was invariably less than would have resulted if all the water in the system had increased its volume from that of normal water to that of ice. Two simple and reasonable explanations were offered: It was suggested that a tightly bound surface layer of water was not able to overcome the influence of the adsorption fields thought to emanate from the mineral surfaces and was, therefore, prevented from assuming the configuration of ice. A more vigorously advanced explanation was that the presence of exchangeable cations on the mineral surfaces and of solute impurities rejected and concentrated by growing ice crystals created an interface that remained unfrozen because it consisted of concentrated brine. The dilatometer method was subsequently employed by many investigators for the purpose of estimating amounts of unfrozen water existing under the imposition of various conditions. One of the most meticulous studies was that of Buehrer and Rose (1943) and the most elegant and complete evaluation of the theory and application of the method was provided by Edlefsen and Anderson (1943). In all important respects, the conclusions of Bouyoucos were verified. Edlefsen and Anderson, however, contended that the effect of the adsorption field emanating from mineral surfaces would create an adsorption pressure. They then derived thermodynamic equations reflecting the effect of a positive adsorption pressure. This was done so as to incorporate the widely accepted view that adsorbed substances were virtually immobilized. Thus, from dilatometer studies, it was possible to envision the bound, interfacial water existing as a fluid brine with a very low freezing point on the one hand, or as a rigid, immobilized adsorbed layer on the other.

The early calorimetric studies of Nersesova (1953, 1954) were designed specifically to reveal the presence of unfrozen interfacial water in frozen materials. Similar work was begun by Lovell (1957) and others in the United States and Canada. The calorimetric method as usually employed involves the transfer of a small sample of frozen soil, previously equilibrated at a given temperature, into a calorimeter filled with liquid at some temperature above $0 \mathrm{C}$. Heat is exchanged between the calorimeter fluid and the sample causing the latter to thaw. After the heat exchange is complete the latent heat of fusion is computed from a heat balance equation containing appropriate terms for the heat capacities of ice, the mineral grains, the unfrozen, interfacial water, and the calorimeter fluid. This calculated heat of fusion is then compared to that expected from the total water content to obtain an estimate of the water that did not freeze.

Results obtained by this method, in general, confirmed the conclusions derived from the earlier dilatometric studies. As summarized by Nersesova and Tsytovich (1963), it became clear that for any frozen soil material the amount of unfrozen water present depends principally upon temperature and that the greatest change in the amount of unfrozen water present occurs in the temperature range 0 to $-5 \mathrm{C}$. Except for water contents-so low that it is difficult or impossible to form ice, the unfrozen interfacial water is virtually independent of water content. At any given temperature, on the other hand, the governing factors are the specific surface area, the nature and intensities of the interfacial interaction, and the nature and amounts of soluble substances present. As usually employed, the calorimetric method cannot distinguish an interface of fluid brine from an interface consisting of rigidly adsorbed water. 


\section{SPATIAL DISTRIBUTION OF UNFROZEN WATER}

Although it has been widely believed that the unfrozen water exists at the interface between the mineral grains and ice and in crevices and capillaries where the radius of curvature is sufficiently small to prevent ice propagation, because of the nature of the phenomena and the microscopic dimensions involved direct evidence as to the location of and disposition of the unfrozen water is scarce. To obtain information on this point, we recently studied the montmorillonite-water system by X-ray diffraction during freezing and thawing (Anderson and Hoekstra, 1965b). Montmorillonite was selected for several reasons: it is a $2: 1$, expandinglattice clay capable of imbibing large amounts of interlamellar water and is therefore amenable to study by X-ray diffraction; it has a high, well defined specific surface area and a high cation exchange capacity; the atomic configuration and properties of its surfaces are well established; and, finally, it is an important type of silicate mineral and is obtainable in sufficient quantities of established purity.

Several homoionic clay-water mixtures were made and in the thawed condition were observed to have interlamellar water contents ranging from low to high. On freezing, the initial high $\mathrm{d}(001)$, spacings of the lithium-and sodium- montmorillonite first decreased to about $19 \AA$ and at about $-10 \mathrm{C}$ collapsed further to $16 \AA$. Since the thickness of the clay lattice is about $10 \AA$ and the diameter of the water molecule is about $3 \AA$ it can be seen that this corresponds to about three and two molecular layers of water, respectively, remaining in the interlamellar space of the frozen montmorillonite clay. On melting, the interlamellar spacings quickly expanded to their initial high values. Evidently, on first freezing all but about three monomolecular layers of the interlamellar water migrates out of the interlamellar space into the pore space where it freezes. The remaining interlamellar water must constitute a significant portion of the "unfrozen water" of the dilatometric and calorimetric studies. Figures 7 and 8 illustrate the results. Figure 8 is roughly to scale and correctly depicts the relative thickness of the individual lamella and the interlamellar spacings; it is also correct in schematically illustrating warped or bent particles. It is not possible on this scale to show more than about $1 / 10$ the longitudinal extent of the particle sheets, however. Edge to face contacts are shown although edge to edge, ribbon-like structures may also exist.

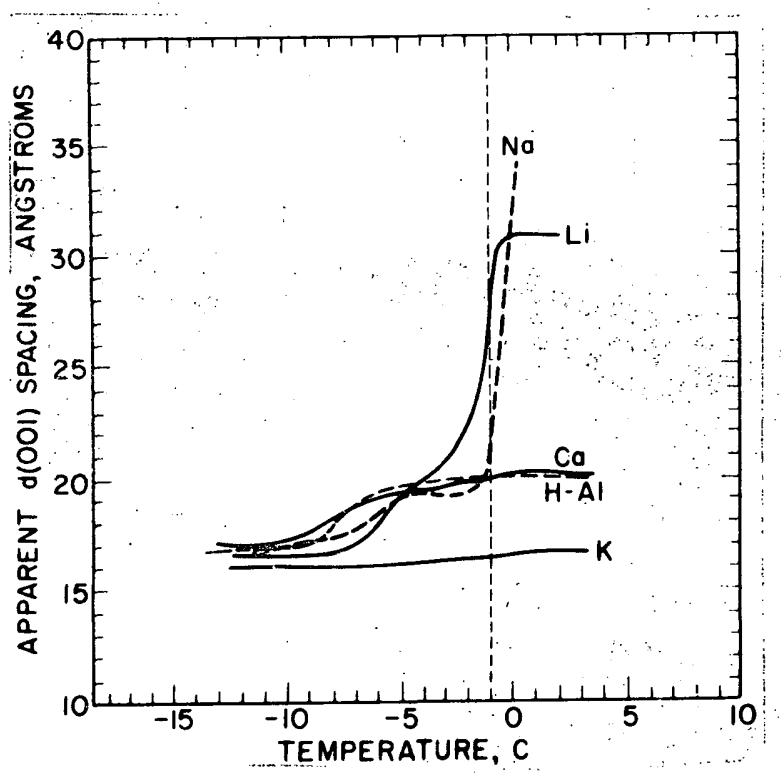

Figure 7. The change in d(001) spacing for several homoionic Wyoming bentonite (montmorillonite) clays during the warming portion of a freeze-thaw cycle. The dotted vertical line indicates the temperature at which the diffraction pattern of ice was last seen. 

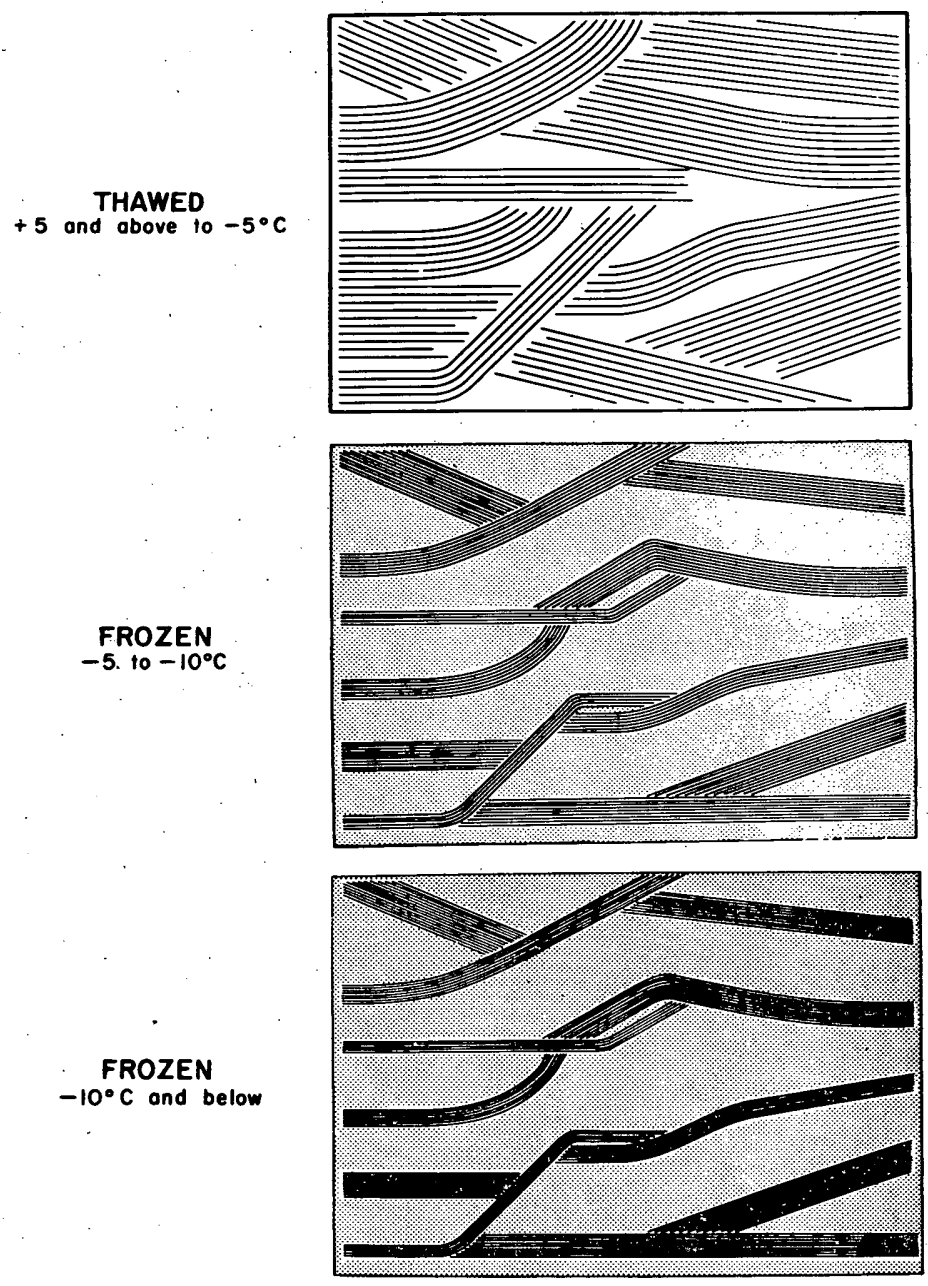

Figure 8. Illustration of structural changes due to changes in interlamellar spacing during freezing and thawing.

Lattice collapse and reexpansion on freezing and subsequent thawing was rapid, invariably complete in 1 or 2 minutes, illustrating the mobility of the interlamellar water. When the temperature was raised in increments above $-10 \mathrm{C}$, the lattice spacings increased even though the diffraction pattern of ice I was still present. This is unequivocal evidence of a progressive partial melting of the ice; the water thus liberated is evidently drawn back into the interlamellar space in accordance with the opinion of Tsytovich, stated as early as 1945 (Nersesova and Tsytovich, 1963), that "the amounts, composition and properties of unfrozen water contained in frozen soils are not constant but change with alterations in external conditions, maintaining a state of dynamic equilibrium." It was also observed that the lattice spacings of the frozen clays depended only on temperature and were virtually independent of water content.

Data on the amount of unfrozen water in frozen montmorillonite-water mixtures have been published by Buehrer and Aldrich (1946), Hemwall and Low (1955), Kolaian and Low (1963) and Nersesova and Tsytovich (1963). By comparing these data with the information derived from the $X$-ray study, an attempt to determine whether or not a significant portion of the unfrozen water is located in the extralamellar pore space is possible. For lithium-, sodium- and potassium-montmorillonites containing about $1.8 \mathrm{~g}$ water per g clay, Kolaian and Low (in general agreement with Buehrer and Aldrich and with Hemwall and Low) 
report $0.83,0.99$ and $0.75 \mathrm{~g}$ unfrozen water per $\mathrm{g}$ clay, respectively, at $-5 \mathrm{C}$; at $-15 \mathrm{C}$ their figures are $0.81,0.86$ and 0.72 . Taking the specific surface area of montmorillonite to be $800 \mathrm{~m}^{2}$ per g clay and assuming an interlamellar spacing of $19 \AA$ for their lithium - and sodium-montmorillonites (corresponding to an interlamellar water content of about $0.37 \mathrm{~g}$ water per $\mathrm{g}$ clay) it would appear that about $2 / 3$ of the unfrozen water must exist in extralamellar pore spaces. In potassiummontmorillonite-water mixtures the lattice c-axis spacings seldom, if ever, exceed $16 \AA$ : hence, in this case, it would appear that more than $2 / 3$ of the unfrozen water must exist outside the interlamellar regions.

The data of Kolaian and Low were obtained by the calorimeter method. In computing the unfrozen water contents, it was assumed that the latent heat. of phase change and the specific heat of the clay-adsorbed water are no different than those of normal water, although it was recognized that these assumptions might subsequently be shown to introduce significant errors. As will shortly be demonstrated, the latent heat of phase change of the interfacial water is less than that of normal water. Consequently, unfrozen water contents determined by this method are probably too high. The data of Buehrer and Aldrich were obtained by the dilatometer method, which also involves a doubtful assumption that the densities of water and the dilatometer fluid are unaffected by interactions at interfaces.

According to Anderson and Low (1958), the density of water adsorbed by montmorillonite is less than that of pure water in bulk; hence, the unfrozen water contents obtained by the dilatometer method also probably are too high. The most recently reported calorimetric investigation of frozen montmorillonite-water mixtures yielded much lower unfrozen water contents than those given above (Nersesova and Tsytovich, 1963). Experimental details were not given, so although the investigators were aware that the latent heat of phase change must be less than the normal latent heat of freezing (Martynov, 1956); it is not known whether or not a correction for this effect was applied. However, for a sodium-montmorillonite called "ascangel" at $-5 \mathrm{C}$, they report $0.43 \mathrm{~g}$ unfrozen water per $\mathrm{g}$ clay. This value is only slightly larger than a value estimated by $\mathrm{Wu}$ (1964) for sodium-montmorillonite $10.3 \mathrm{~g}$ unfrozen water per $\mathrm{g}$ clay) from nuclear magnetic resonance data at $-3 \mathrm{C}$, and it is in good agreement with the $0.37 \mathrm{~g}$ interlamellar water per g clay found by $\mathrm{X}$-ray diffraction. Their data are shown as a function of temperature in Figure 9.

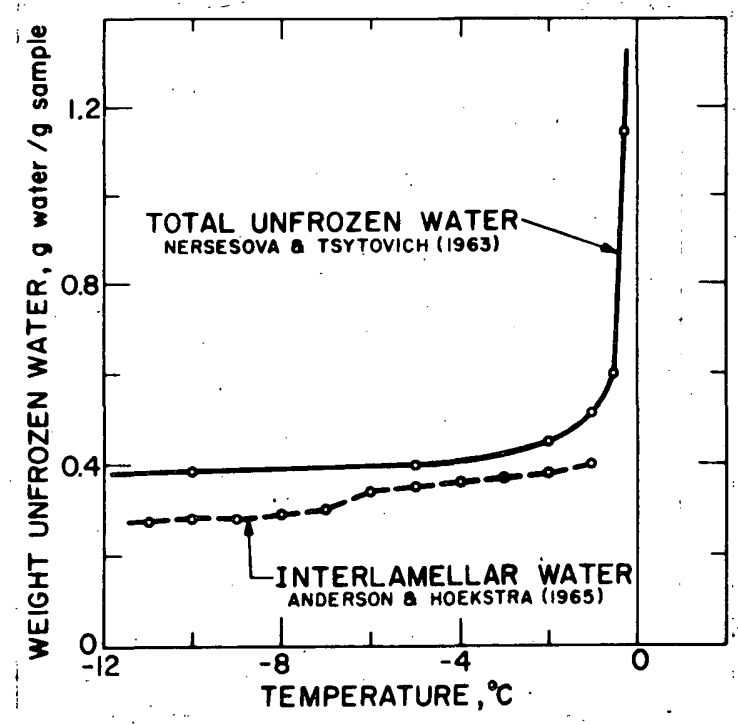

Figure 9. Total unfrozen water and unfrozen interlamellar water in sodium-bentonite as a function of temperature.
It is clear that substantial amounts of unfrozen water exist in frozen montmorillonite-water mixtures, and from the $\mathrm{X}$-ray diffraction data it is ciear that part of this water must be located in the interlamellar space. However, the various methods yield conflicting unfrozen water contents, making it impossible to estimate the relative amount of unfrozen water located in extralamellar regions. The dilatometric and calorimetric methods lead to estimates that probably are too high whereas the $X$-ray diffraction method cannot prove the existence or yield estimates of the amount of unfrozen water located outside the interlamellar space. The question has been at least partly resolved, however, by the results of heat capacity measurements (Anderson, 1966). 
The heat capacity of a frozen montmorillonite-water mixture may be written as a sum of four terms, one for each phase plus a term to account for the latent heat involved in the possible change in the relative amount of ice and unfrozen water during the measurement. Thus

$$
Q=\left[\left(C_{c} M_{c}\right)+\left(C_{i} M_{i}\right)+\left(C_{u} M_{u}\right)\right] \Delta T+\int_{T_{1}}^{T_{2}} \Delta \bar{H}_{f}\left(\frac{\partial M_{u}}{\partial T}\right) d T .
$$

In eq $7, Q$ is the heat capacity per $g$ of mixture over the temperature interval $\Delta \mathrm{T}$; $C_{C}, C_{i}$, and $C_{u}$ are the partial specific heat capacities of the clay, ice and unfrozen water, respectively; $M_{c}, M_{i}$, and $M_{u}$ are the weights of the three phases, clay, ice, and unfrozen water, respectively; and $\Delta \overline{\mathrm{H}}_{\mathrm{f}}$ represents the latent heat of phase change of the unfrozen water.

Since the total weight of water, $M_{W}$, present is

$$
M_{w}=M_{i}+M_{u}
$$

eq 7 becomes

$$
Q=\left[C_{i} M_{w}+C_{c} M_{c}+M_{u}\left(C_{u}-C_{i}\right)\right] \Delta T+\int_{T_{1}}^{T_{2}} L\left(\frac{\partial M_{u}}{\partial T}\right) d T
$$

Dividing through by $\Delta \mathrm{T}$ and $\mathrm{M}_{\mathrm{c}}$ yields

$$
q=C_{i} w_{w}+\left[C_{c}+w_{u}\left(C_{u}-C_{i}\right)\right]+\frac{1}{\Delta T} \int_{T_{1}}^{T_{2}} \Delta \bar{H}_{f}\left(\frac{\partial W_{u}}{\partial T}\right) d T
$$

where $q$ is now the heat capacity of the mixture per degree per unit weight of clay; $W_{u}$ and $W_{W}$ are the unfrozen water content and the total water content, respectively. Notice that eq 10 is linear with $\mathrm{W}_{\mathrm{w}}$, provided the last two terms are constant.

The first term in the brackets is the partial specific heat of the clay and to a good approximation can be regarded as independent of water content and, therefore, can be taken as constant. It was pointed out earlier that $\mathrm{w}_{\mathrm{u}}$ is virtually independent of water content and, therefore, can be taken as constant for a given temperature (for the small temperature interval, $\Delta \mathrm{T}=0.01 \mathrm{C}$, employed in the determinations, a constant average value may be used). Since the unfrozen water content does not vary with $\mathrm{W}_{\mathrm{w}}$, it is unlikely that the partial specific heat of the unfrozen water would change significantly with water content; hence, the second term in brackets also can be taken as constant. If the conditions of measurement are the same from sample to sample, the limits of integration and $\Delta T$ will be constant. Moreover, if $W_{u}$ is independent of $W_{w}$ and dependent only upon $T$ then it may be argued that the functional relationships between $\left(\partial \mathrm{W}_{\mathrm{u}} / \partial \mathrm{T}\right), \Delta \overline{\mathrm{H}}_{\mathrm{f}}$ and $\mathrm{T}$ will be the same for each sample. This being the case, the last term in eq 10 may also be regarded as constant. Therefore, a plot of the heat capacity (per unit weight of clayl of a frozen clay-water mixture versus its total water content is expected to yield a straight line with a slope equal to the partial specific heat in the mixture and an intercept equal to the sum of the last two terms in eq 10 . The plot will depart from linearity when the water content diminishes below the point at which the ice phase disappears, for at this point the unfrozen water content, $w_{u}$, must also diminish. 


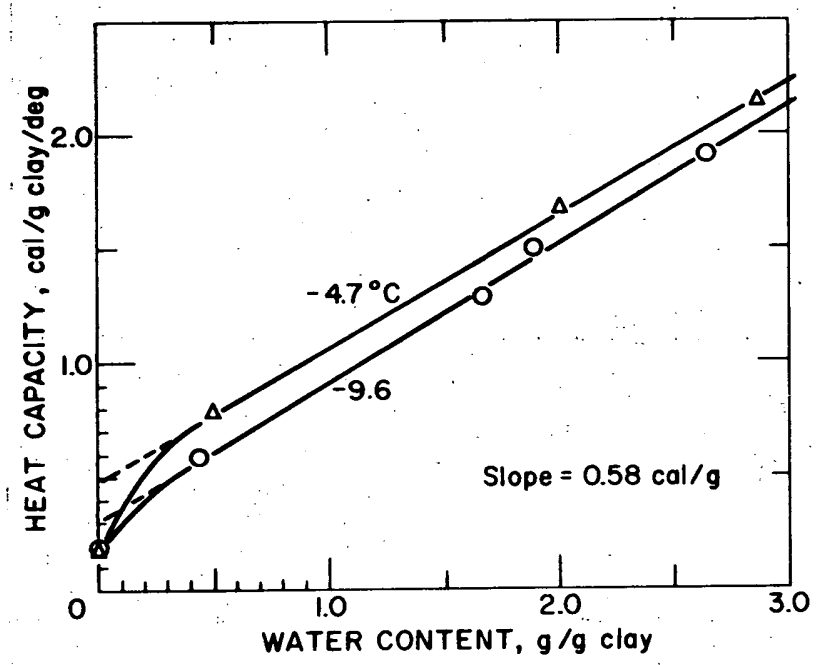

Figure 10. The heat capacity of frozen $\mathrm{Na}$-montmorillonite water mixtures.
The heat capacity of frozen sodiummontmorillonite-water mixtures as a function of water content is shown in Figure 10. For water contents above about $0.5 \mathrm{~g}$ water per $\mathrm{g}$ of clay the plot is linear, again confirming the fact that the unfrozen water content is practically independent of total water content (or ice content). Reasonable values of the unfrozen water contents, determined by picking the point at which the curve departs from linearity, are 0.3 and $0.4 \mathrm{~g}$ per $\mathrm{g}$ clay at $-9.6 \mathrm{C}$ and $-4.7 \mathrm{C}$, respectively. No doubt it can be argued that the values are not very accurately defined because of the paucity of data and the difficulty of locating the point at which curvature begins. However, roughly the same values result from the extrapolated intercepts when reasonable values are substituted for the

parameters in eq 10; it is easily shown that the extrapolated intercepts are incompatible with the high unfrozen water contents resulting from earlier dilatometric and calorimetric determinations. The unfrozen water contents obtained from heat capacity measurements agree with those of Nersesova and Tsytovich and with the NMR data of Wu. Taken together with the unfrozen interlamellar water contents determined by X-ray diffraction, they indicate that most of the unfrozen water in frozen montmorillonite-water mixtures can be accommodated, and is, therefore, thought to be located in the interlamellar regions. At $-4.7 \mathrm{C}$ and $-9.6 \mathrm{C}$ the data indicate that the amount of unfrozen water present is equivalent to a surface-held layer only one or two molecular diameters in thickness; assuming that the water is uniformly distributed over the entire surface $\left(800 \mathrm{~m}^{2} / \mathrm{g}\right)$ of the clay.

Hoekstra and Chamberlain (1964), and Hoekstra (1965) have shown that although the electrical conductance of montmorillonite-water mixtures is reduced upon freezing, the reduction is surprisingly small. The data can be explained only by postulating continuous pathways for movement of the exchangeable cation and other ionic charge carriers. Since the exchangeable cations are constrained in regions close to the mineral surface and since solutes tend to be expelled from an advancing ice-water interface, the only tenable view is that the unfrozen water exists in a layer between the mineral surface and the ice. The high mobility of the unfrozen interfacial water is indicated by the rapidity of lattice expansion and collapse on freezing and thawing, and by the high electrical conductance and the occurrence of electroosmosis in frozen montmorillonite-water mixtures. Undoubtedly, some unfrozen water exists outside the interlamellar space, but as indicated in Figures 7 and 9, the amounts need not be large except possibly at temperatures between -5 and $0 \mathrm{C}$.

\section{NATURE OF THE ICE PHASE}

Martynov (1959) has cited an X-ray diffraction study to show that, on freezing, soil water crystallizes as normal, hexagonal ice. Brzhan, on the other hand, maintained that, in frozen silica gel, water crystallizes in a different form, possibly the low pressure cubic form that is normally stable only below $-80 \mathrm{C}$. It is well established that microscopic bodies of segregated ice in earth materials exist as normal hexagonal ice (Konnova, 1961) and Kumai (1957) has shown electron 
micrographs of normal hexagonal ice crystals nucleated by clay particles 10 microns or less in diameter. Still the question remains: what is the crystallographic form of sub-microscopic ice crystals immediately adjacent to silicate surfaces? Details of the study referred to by Martynov have not become available but data from a similar X-ray diffraction study by Anderson and Hoekstra (1965a) are given in Table II. It is evident in Table II that the observed d-spacings due to water in the frozen clays correspond to those of normal ice $\pm 0.02 \AA$. Moreover, no anomalous, unidentifiable peaks were detected. These results were obtained with quick frozen clays at low water contents. Again, taking the specific surface area of montmorillonite to be $800 \mathrm{~m}^{2}$ per $\mathrm{g}$ clay, the equivalent thickness of the water films distributed over the entire surface of the clay is of the order of two or three molecular diameters, just the thickness of the unfrozen interfacial water; normal, hexagonal ice formed in spite of the forces that prevent a large portion of the water from freezing. Numerous determinations at higher water contents and lower temperature gave similar results; in all cases only d-spacings attributable to ice I were detected.

Table II. X-ray diffraction intensities, $I / I_{002}$ for crystalline water in various frozen clay-water pastes.

\begin{tabular}{|c|c|c|c|c|c|c|c|c|}
\hline $\begin{array}{c}\text { Index } \\
\text { d-spacing } \\
\end{array}$ & $\begin{array}{l}100 \\
3: 93 \\
\end{array}$ & $\begin{array}{l}002 \\
3.68 \\
\end{array}$ & $\begin{array}{l}101 \\
3.45 \\
\end{array}$ & $\begin{array}{l}102 \\
2.68 \\
\end{array}$ & $\begin{array}{l}110 \\
2.26 \\
\end{array}$ & $\begin{array}{r}103 \\
2.069 \\
\end{array}$ & $\begin{array}{l}112 \\
1.92 \\
\end{array}$ & $\begin{array}{l}203 \\
1.52 \\
\end{array}$ \\
\hline Hexagonal ice* & 10 & 100 & 20 & 15 & 10 & 50 & 10 & 15 \\
\hline Silica gel† & $\mathbf{S}$ & VS & - & - & $S$ & - & $\mathbf{M}$ & - \\
\hline $\begin{array}{l}\text { Hydrogen-bentonite } \\
\left(0.54 \mathrm{~g} \mathrm{H}_{2} \mathrm{O} / \mathrm{g} \text { clay }\right)\end{array}$ & 68 & 100 & 24 & 14 & 1 & 38 & - & - \\
\hline $\begin{array}{l}\text { Lithium-bentonite } \\
\left(0.74 \mathrm{~g} \mathrm{H}_{2} \mathrm{O} / \mathrm{g} \text { clay }\right)\end{array}$ & 64 & 100 & 32. & - & - & - & - & - \\
\hline $\begin{array}{l}\text { Sodium-bentonite } \\
\left(0.99 \mathrm{~g} \mathrm{H}_{2} \mathrm{O} / \mathrm{g} \text { clay) }\right.\end{array}$ & 294 & 100 & 144 & 33 & 95 & 50 & 33 & - \\
\hline $\begin{array}{l}\text { Potassium-bentonite } \\
\left(0.60 \mathrm{~g} \mathrm{H}_{2} \mathrm{O} / \mathrm{g} \text { clay) }\right.\end{array}$ & 76 & 100 & 35 & 23 & 17 & 29 & - & - \\
\hline $\begin{array}{l}\text { Calcium-bentonite } \\
\left(0.33 \mathrm{~g} \mathrm{H}_{2} \mathrm{O} / \mathrm{g} \text { clay }\right)\end{array}$ & 200 & 100 & 80 & 40 & 80 & 60 & - & - \\
\hline $\begin{array}{l}\text { Kaolinite } \\
\left(0.40 \mathrm{~g} \mathrm{H}_{2} \mathrm{O} / \mathrm{g} \text { clay }\right)\end{array}$ & 92.5 & 100 & 70.3 & 38.6 & 56.6 & 58.4 & 21.1 & - \\
\hline $\begin{array}{l}\text { Halloysite } \\
\left(0.90 \mathrm{~g} \mathrm{H}_{2} \mathrm{O} / \mathrm{g} \text { clay }\right)\end{array}$ & 106 & 100 & 104 & 31 & 60 & 43 & 40 & - \\
\hline
\end{tabular}

*ASTM Card (Dennison; Phys. Rev. 17:20 (1927)

† Brzhan, 1959: $S$ = Strong; VS = Very Strong; $M=$ Medium

The observed relative intensities of the diffraction peaks showed consistent deviations from the random powder pattern. This is best explained by postulating a preferred orientation of the microscopic ice crystals in the frozen clay. The data indicate that a majority of the ice crystals were oriented so that their c-axes were in a plane parallel to that of the goniometer stage. During preparation of the sample, attempts were made to obtain preferential orientation of the individual clay platelets by repeated remolding of the sample with a spatula. Subsequent observation of greatly enhanced $d(001)$ diffraction peaks of the montmorillonite and kaolinite clays proved that the $c$-axes of the clay platelets were preferentially 
oriented in the direction perpendicular to the plane of the goniometer stage. The fact that the relative intensities of the (101),(102), (103), (112) and (203) spacings did not diminish consistently, together with the fact that the (101) reflection was intensified relative to the (001) in most instances, suggests that there may be some tendency toward parallel orientation of this face; however, the main effect is the relative intensification of the (100) reflection.

One might conclude from these results that the clay particles had some influence on the orientation of the ice crystals in the frozen clays. In a preceding section it was mentioned that various hydrogen-bonded water networks might propagate on surfaces of the layer lattice silicates (Hendricks and Jefferson, 1938; Macey, 1942 and Mathieson and Walker, 1954). The configuration of the hexagonal network of the oxygen atoms making up the surface of the 2:1 lattice clays could provide both the foundation and the template on which the water network might be built up. This line of reasoning has lead to speculation that clay particles might effectively act as ice-nucleating agents in the atmosphere. Kumai and Francis (1962) have shown that clays do perform this function; and Schaefer (1958), and Mason and Maybank (1958), among others, have reported systematic studies of the relative nucleating efficiency of various silicate-clay minerals.

The hydrogen-bonded, adsorbed water structures so far postulated have their c-axes aligned with that of the clay lattice. If the clay lattice and its adsorbed water hull were to nucleate ice, it is to be expected that the ice formed would have its c-axes similarly aligned; the data in Table II do not support this view and it is noteworthy that in the nucleation studies cited above it was found that montmorillonite does not seem to be very efficient in this respect. From the foregoing discussion of the nature and distribution of the unfrozen interfacial water, it is not to be expected that ice actually bonds directly to the surface oxygens of the clay. It is remarkable, however, that, as the data in Table II.show, there nevertheless is evidence of epitaxy. Whether or not the observed preferential orientation can be attributed to forces emanating from the mineral surface cannot yet be answered with certainty, but it is not an unlikely possibility.

Brzhan's data do not support his contention that an unusual form of ice existed in his frozen silica gel. As is evident in Table II, all the diffraction peaks reported can be attributed to hexagonal ice. The data do show unusually strong (100) and (110) diffraction intensities. In the absence of evidence to the contrary this is most reasonably explained in terms of a preferential orientation of the ice crystals in the frozen silica gel; the evidence given does not warrant postulating a new crystallographic form of ice. However, Litvan (1963) has presented extensometer data indicating possible phase changes in the interfacial water imbibed by porous vycor glass as the temperature was lowered from 0 to about $-180 \mathrm{C}$. Depending upon water content, phase changes appeared to occur at $-7,-22$ and below $-50 \mathrm{C}$. The same system was investigated simultaneously with an extensometer and a calorimeter by Antoniou (1964). From anomalies in the variation of the apparent heat capacity with temperature, he concluded that at least two kinds of phase transformations occurred below the normal freezing point of water. The possibility of anomalous phases in frozen montmorillonite-water mixtures is also indicated in the work of Kato (1959). From differential thermograms, he detected two exothermic peaks, one at about -5 and one at about $-20 \mathrm{C}$. He interpreted the peaks as being due to the incremental freezing of clay-held, interfacial water although the existence of an unusual solid phase is a possibility. The existence of unusual forms of ice at interfaces has not been unequivocally established yet (except, of course, for the formation of cubic ice by vapor condensation on a substrate at $-80 \mathrm{C}$ or lower) and most of the available evidence indicates that, even at interfaces, ice $\mathrm{I}$ is present at temperatures above $-80 \mathrm{C}$; nevertheless, until the evidence becomes more definitive, the question must be kept open. 


\section{PHASE RELATIONSHIPS}

The concepts and evidence presented in the foregoing pages make it possible in qualitative terms to construct the phase diagram for the equilibria between the unfrozen, interfacial water, water vapor, and ice. Figure 11 is the phase diagram (not to scale) near the triple point for pure water and for water imbibed to three different extents by montmorillonite clay. The three different water contents may be visualized as corresponding to interfacial water layers of three different thicknesses. Point $a$ is the triple point, lines $a-a^{\prime}$ and abcd are the vapor pressure curves for the liquid and solid, respectively, and line a-a" describes the effect of pressure on the melting point, for pure water. Point $b$ is the triple point for the interfacial water in montmorillonite clay at a water content of $40 \%$. The point is displaced to the left and downward along the vapor pressure curve of ice by an amount equal to the freezing point depression. Placing the point on the vapor pressure curve of ice is justified by the fact that normal, hexagonal ice is observed to form when the mixture freezes (the effect of ice crystal size on the vapor pressure is neglected for present purposes). Line $b-b^{\prime}$ is the water vapor pressure curve for the thawed clay containing $40 \%$ water. At all temperatures the water vapor pressure of the moist clay is lower than that of the pure liquid by an amount characteristic of the clay at the given water content.

Line $b-b^{\prime \prime}$ is the line describing the effect of pressure on the equilibrium between ice and the clay-held water. This line is seen to have been drawn with a smaller negative slope than the corresponding line for pure water. For pure water, the slope is about $140 \mathrm{~atm}$ per degree change in the melting point; for the clay-held water it is less, illustrating the fact that the ice in frozen soils and clays is more easily melted by the imposition of pressure. To verify this important conclusion, consider the following transitions:

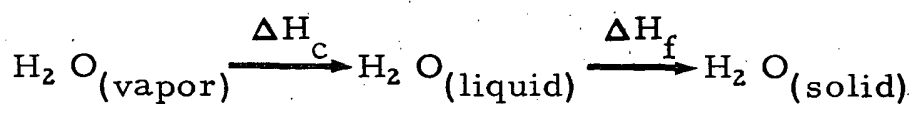

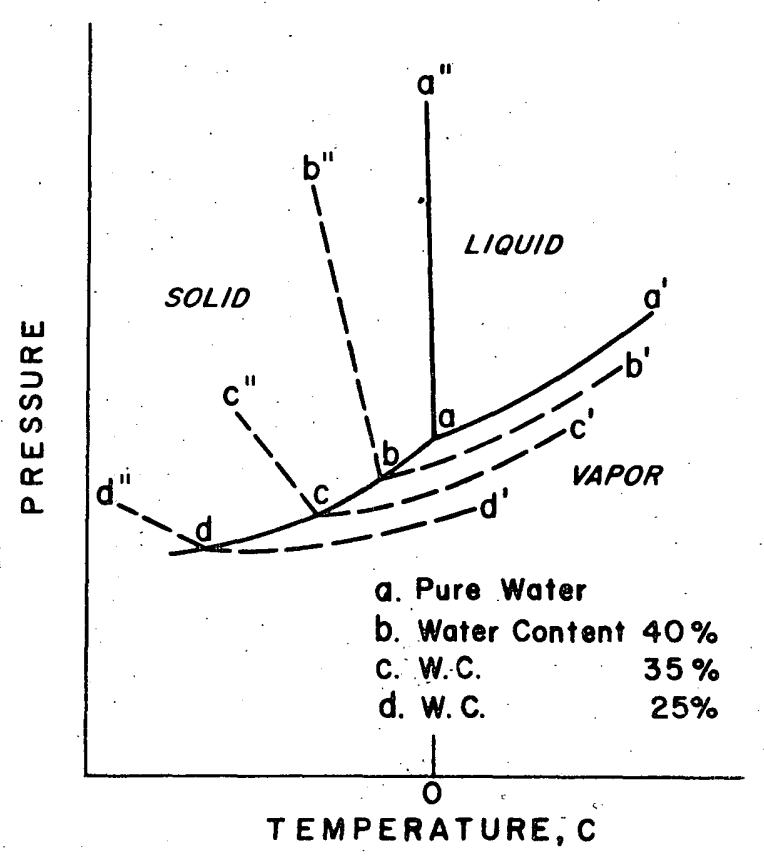

Figure 11. Schematic phase diagram for water imbibed by montmorillonite showing the effect of clay surfaces on the vapor pressure, the freezing point and the slope of the solid-liquid equilibria (not to scale). 


$$
\begin{aligned}
& \mathrm{H}_{2} \mathrm{O}_{(\text {vapor })} \stackrel{\Delta \overline{\mathrm{H}}_{\text {ads }}}{\longrightarrow} \mathrm{H}_{2} \mathrm{O}_{(\text {surface })} \stackrel{\Delta \overline{\mathrm{H}}_{\mathrm{fs}}}{\longrightarrow} \mathrm{H}_{2} \mathrm{O}_{(\text {solid) }} \\
& \mathrm{H}_{2} \mathrm{O}_{\text {(vapor) }} \stackrel{\Delta \mathrm{H}_{\mathrm{c}}}{\longrightarrow} \mathrm{H}_{2} \mathrm{O}_{(\text {liquid) }} \stackrel{\Delta \overline{\mathrm{H}}_{\mathrm{w}}}{\longrightarrow} \mathrm{H}_{2} \mathrm{O}_{(\text {surface) }} \stackrel{\Delta \overline{\mathrm{H}}_{\mathrm{fs}}}{\longrightarrow} \mathrm{H}_{2} \mathrm{O}_{(\text {solid) }} .
\end{aligned}
$$

The subscripts denote the state of the water and the three equations describe a series of phase changes. The $\Delta \bar{H}^{\prime}$ 's are the enthalpy changes accompanying the transitions. In some cases they can be clearly identified as familiar latent heats. In eq 12 , however, $\Delta \overline{\mathrm{H}}_{\text {ads }}$ is the differential heat of adsorption (measured calorimetrically or calculated from adsorption isotherms) and $\Delta \overrightarrow{\mathrm{H}}_{f_{S}}$ is the latent heat of freezing interfacial water imbibed by the clay. In eq 13, $\Delta \overline{\mathrm{H}}_{\mathrm{W}}$ is the differential heat of wetting (also measured calorimetrically or computed from adsorption isotherms). For convenience, here, positive values indicate that heat is evolved. Since the initial and final states in the three equations are the same, if the heat effects are measured in such a way that no work is done other than expansion against atmospheric pressure, then by the first law of thermodynamics it follows that

$$
\Delta \overline{\mathrm{H}}_{\mathrm{ads}}=\Delta \mathrm{H}_{\mathrm{c}}+\Delta \overline{\mathrm{H}}_{\mathrm{w}}
$$

and

$$
\Delta \overline{\mathrm{H}}_{\mathrm{fs}}=\Delta \mathrm{H}_{\mathrm{f}}-\Delta \overline{\mathrm{H}}_{\mathrm{w}}
$$

Thus it appears that the latent heat of freezing the clay-held water is less than that of pure water in bulk by an amount equal to the differential heat of wetting. This is reasonable and satisfactorily accounts for that portion of energy given up by the liquid in reaction to surface forces before it subsequently freezes out as normal ice. If experimental values of the differential heat of wetting measured at freezing temperatures were available, the latent heat of freezing clay-held water could be computed directly from eq 15. Alternately, if water vapor adsorption isotherms at several temperatures below freezing were available, the data could be used in conjunction with the Clausius-Clapeyron equation to compute $\Delta \overline{\mathrm{H}}_{\mathrm{ads}}$ from which $\Delta \bar{H}_{w}$ could be extracted by subtracting $\Delta \mathrm{H}_{\mathrm{v}}$, and $\Delta \bar{H}_{\mathrm{fs}}$ could be calculated from the result. As yet, these data have not been obtained but an estimate calculated from the adsorption data of Mooney et al. (1952) for montmorillonite is shown in Figure 12. Below about $0.1 \mathrm{~g}$ water $\overline{\mathrm{per}} \mathrm{g}$ clay the diagram indicates that heat must be supplied to accomplish the transition shown in the last step of eq 12 and 13 meaning that the surface adsorbed state, energetically, is preferred to that of ice. This idea was entertained in a qualitative way by Vernadskiiy in 1933 according to Khakimov (1957). It was considered in relation to the unfrozen water in frozen soil materials by Martynov (1956) but for want of appropriate data he dropped the matter, as did Williams (1963) and Kolaian and Low (1963).

To see the significance of eq 15 vis a vis the phase diagram in Figure 11 , consider the water component in a montmorillonite-water mixture as it exists in equilibrium in two phases, normal ice and unfrozen interfacial water. The condition for equilibrium is that the partial molar Gibbs free energy of the ice $\bar{F}_{u}$ is equal to that of the interfacial water $\bar{F}_{i}$. Thus,

$$
\bar{F}_{u}(T, p)=\bar{F}_{i}(T, p)
$$




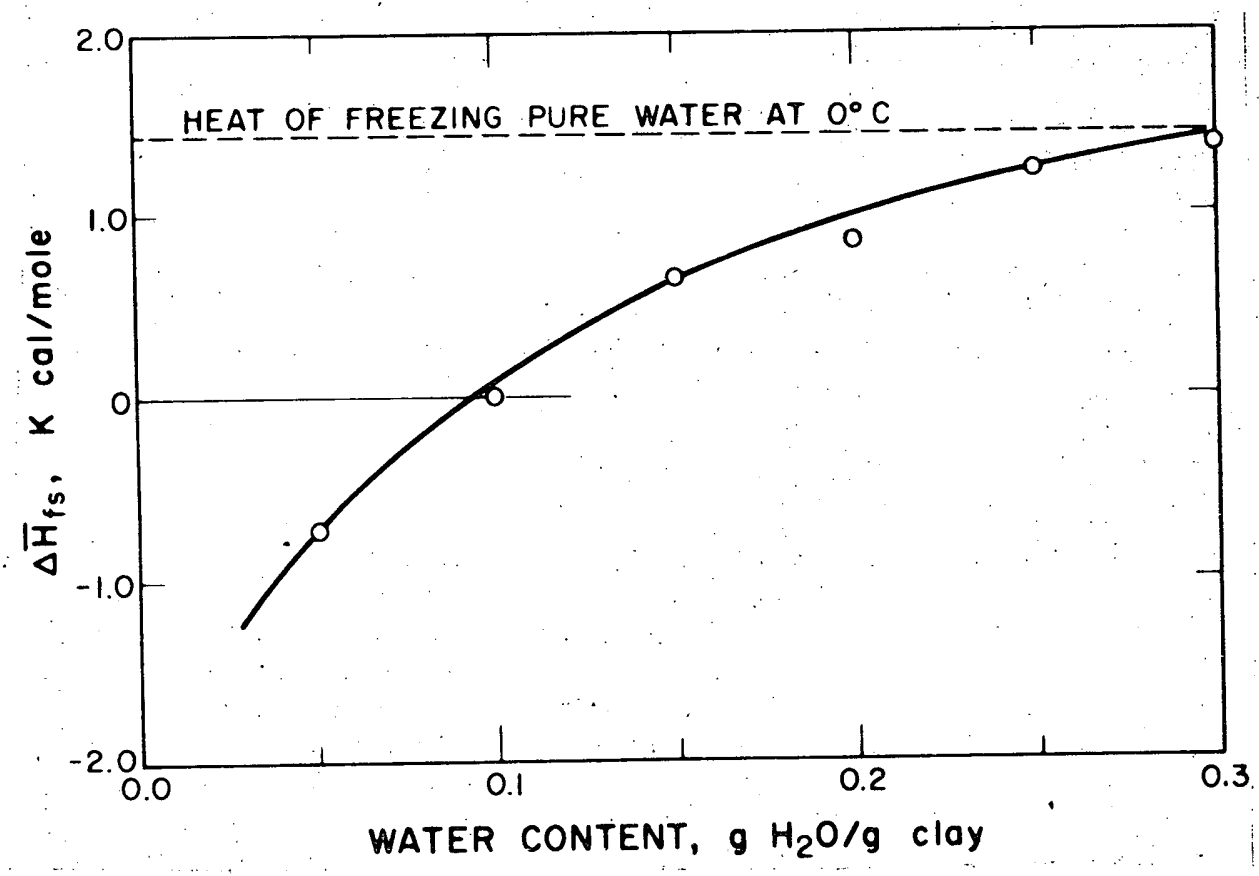

Figure 12. Estimate of the latent heat of freezing clay-held water computed from water vapor adsorption on $\mathrm{Na}-$ montmorillonite.

where $\mathrm{T}$ and $\mathrm{p}$ are temperature and pressure, respectively; other independent variables of state such as the interfacial area, composition, etc. are to be held constant. For a different equilibrium state at a slightly different temperature and pressure, $T+d T$ and $p+d p$,

$$
\bar{F}_{u}+d \bar{F}_{u}=\bar{F}_{i}+d \bar{F}_{i}
$$

It then follows that

$$
\mathrm{d} \overline{\mathrm{F}}_{\mathrm{u}}=\mathrm{d} \overline{\mathrm{F}}_{\mathrm{i}}
$$

Taking the total derivative of eq 18 and identifying the partial derivatives as the partial molar volume, $\bar{V}$, and the partial molar entropy, $\bar{S}$, respectively, one has

$$
d F_{u}=\nabla_{u} d p-\bar{S}_{u} d T
$$

and

$$
d F_{i}=\bar{V}_{i} d p-\bar{S}_{i} d T
$$

Equating and rearranging eq 19 and 20 results in

$$
\frac{d p}{d T}=\frac{\left(\bar{S}_{j}-\bar{S}_{u}\right)}{\left(\bar{V}_{i}-\bar{V}_{u}\right)}
$$


Now by definition

$$
\frac{\Delta \overline{\mathrm{H}}_{f s}}{\mathrm{~T}}=\left(\overline{\mathrm{S}}_{\mathrm{i}}-\overline{\mathrm{S}}_{\mathrm{u}}\right)
$$

in which $\Delta \overline{\mathrm{H}}_{\mathrm{fs}}$ is the difference in partial molar enthalpy between ice and water; returning to conventional practice $\Delta \overline{\mathrm{H}}_{\mathrm{fs}}$ here is negative reflecting the evolution of heat of freezing. After substituting this identity in eq 21 one obtains

$$
\frac{\mathrm{dp}}{\mathrm{dT}}=\frac{\Delta \overline{\mathrm{H}}_{\mathrm{fs}}}{\mathrm{T} \Delta \overline{\mathrm{V}}} .
$$

Equation 23 describes the lines $a-a^{\prime \prime}, b-b^{\prime \prime}$, etc. in Figure 11. In predicting the slope of lines $b-b^{\prime \prime}, c-c^{\prime \prime}$ and $d-d^{\prime \prime}$, two principal factors must be simultaneously considered: the reduction in the freezing temperature, $T$, and the diminished latent heat of freezing $\Delta \overline{\mathrm{H}}_{\mathrm{fs}}$. Reliable data from which the slopes could be computed are not available; however, the estimates of $\Delta \bar{H}_{f s}$ in Figure 12 together with freezing point depressions estimated from Figure 9 indicate that the decrease in $\Delta \overline{\mathrm{H}}_{\mathrm{fs}}$ predominates. For this reason, Figure 12 shows a progressive decrease in slope with decreasing water content. Until the pressure effect can be measured directly or until accurate determinations of $\Delta \bar{H}_{f s}$ at the temperature of freezing are made, however, the magnitude of the slopes of the solid-liquid line must remain in doubt.

The discussion of eq 23 has so far omitted consideration of $\Delta \bar{V}$ but it could be an important factor if it, like $T$, can become very small. The specific volume of ice is about $10 \%$ greater than that of water at $0 \mathrm{C}$ but according to Anderson and Low (1958) the specific volume of the interfacial water in montmorillonite is as much as $3 \%$ greater than that of pure bulk water so that in this case $\Delta \bar{V}$ ought to be reduced accordingly; moreover it appears that as the temperature is lowered, $\Delta \bar{V}$ for a given thickness of interfacial water also decreases (Anderson, 1958) but the rate of decrease and the final limiting value have not yet been determined. It is thought that the effect of a decreasing $\Delta \bar{V}$ is relatively minor in comparison with the influence of $\Delta \bar{H}_{f s}$ and $T$, but since in principle nothing prevents $\Delta \bar{V}$ from going to zero as well as $\Delta \bar{H}_{f s}$ and $T$, the final answer awaits further experimental work.

The consequences of a trend toward decreasing slopes of the solid-liquid lines with decreasing water contents are many. Assuming that the trend is real, ice immediately adjacent to a montmorillonite surface is much more susceptible to pressure melting than is bulk ice, and this may turn out to be true for many surfaces. One concludes, therefore, that the application of pressure must increase the thickness of the unfrozen, interfacial water. This conclusion is important in the theory of ice segregation and frost heaving for it implies that, at a given temperature, the build-up of heaving pressures, or the external application of pressure, acts to increase the thickness and mobility of the interfacial water and would tend to make the process of ice lens growth self perpetuating. Particle migration in ice in response to thermal gradient has been demonstrated by Corte (1962), and Hoekstra and Miller (1965). The application of an external pressure would be expected to enhance the rate of particle migration at a given temperature and application of sufficiently high pressures might induce particle migration at quite low temperatures. The effect of pressure melting at the interface separating ice from other solid surfaces ought to be considered in explaining wire migration experiments of the type recently reported by Telford and Turner (1963). They measured the rate of passage of a thin steel wire, loaded at both ends, through a block of ice at several loads and temperatures. The results cannot be explained by ordinary pressure melting, and consequently were interpreted as evidence of an unfrozen liquid-like interface separating the wire surface from the ice. However, from the foregoing it is clear that the thickness of the liquid-like interface 
might depend significantly on pressure and that, in this sense, pressure melting ought to be involved in interpreting the results. Pressure melting at the interface is also of obvious importance in the phenomena of ice adhesion, either from the standpoint of effecting ice release or of stabilizing the adhesive bond.

The conclusion illustrated in Figure 11, that the slopes of the solid-liquid lines diminish with diminishing thickness of the interfacial layer, has been reasonably well established by the foregoing argument; it is also supported to some extent by experiment. The argument predicts that increasing the external pressure will increase the thickness of the interfacial water layers by pressure melting and thus at a given temperature will increase the unfrozen water content. Tsytovich (1959) has published data confirming this prediction. For montmorillonite containing $46 \%$ water at $-5.8 \mathrm{C}$, the unfrozen water content is reported to have increased by about $3 \%$ when the pressure was increased by about five atmospheres. Experimental verification in other ways is to be expected. In the meantime Figure 11 may be provisionally accepted as a hypothesis for the guidance of future work. Regarding future work, data on $\Delta \overline{\mathrm{H}}_{\mathrm{fs}}$ and $\Delta \overline{\mathrm{H}}_{\mathrm{a}}$ are needed. Although the existence of unfrozen interfacial water is well established, the properties of the interface are only vaguely understood; data on the partial molar volume, partial molar heat capacity and other thermodynamic properties are needed. In addition, improved phenomenological descriptions of diffusional processes, of dielectric and magnetic relaxation, and of the miscibility and dissolving power of the interface are needed. Finally, the existence of phase changes in the interfacial water at low temperatures needs more investigation. If anomalous phases are shown definitely to exist, their properties and conditions for existence should be determined.

\section{LITERA TURE CITED}

Anderson, D. M. (1958) Density of water adsorbed by Wyoming bentonite, Ph. D. Thesis, Purdue University.

(1966) Phase composition of frozen montmorillonite-water mixtures from heat capacity measurements, Soil Science Society of America, Proceedings (In press). Also USA CRREL Research Report 218.

and Hoekstra, P. (1965a) Crystallization of clay-adsorbed water, Science, vol. 149, p. 318-319.

(1965b) Migration of interlamellar water during freezing and thawing of Wyoming bentonite, Soil Science Society of America, Proceedings, vol. 29, p. 498-504. Also USA CRREL Research Report 192.

and Low, P.F. (1958) Density of water adsorbed by lithium-, sodium-, and potassium-bentonite, Soil Science Society of America, Proceedings, vol. 22, p. 99-103.

, Leaming, G.F., and Sposito, G. (1963) Volume changes of a thixotropic sodium-bentonite suspension during sol-gel-sol transition, Science, vol. 141, p. 1040-1041.

Antoniou, A.A. (1964) Phase transformations in porous glass, Journal of Physical Chemistry, vol. 68, p. 2754-2764.

Bernal, J. D. and Fowler, R.H. (1933) A theory of water and ionic solution with particular reference to hydrogen and hydroxyl, Journal of Chemical Physics, vol. 1, p. 515.

Bouyoucos, G.J. (1916) The freezing point method as a new means of measuring the concentration of the soil solution directly in the soil, Michigan Agricultural Station Technical Bulletin 24, p. 1-44. 


\section{LITERATURE CITED (Cont'd)}

Brill, R. (1957) Structure of ice, U.S. Army Snow, Ice and Permafrost Research Establishment (USA SIPRE) Report 33. Also Angewandte Chemie (Inter national Edition), vol. 1, p. 563-612 (1962).

Brzhan, V.S. (1959) An X-ray study of the crystallization of sorbed water, Colloid Journal (USSR), vol. 21, p. 621-624.

Buehrer, T.F. and Aldrich, D. G. (1946) Studies in soil structure. VI: Water bound by individual soil constituents as influenced by puddling, Univer sity of Arizona Technical Bulletín No. 110.

and Rose, M.S. (1943) Studies in soil structure. V: Bound water in normal and puddled soils, Arizona Agricultural Experiment Station Technical Bulletin No. 100.

Corte, A. E. (1962) Vertical migration of particles in front of a moving freezing plane, Journal of Geophysical Research, vol. 67, p. 1085-1090.

Davis, C.M. and Litovitz, T.A. (1965) Two state theory of the structure of water, Journal of Chemical Physics, vol. 42, p. 2563-2576.

Dufour, L. and Defay, R. (1963) Thermodynamics of clouds. New York: Academic Press.

Edlefsen, N.E. and Anderson, A. B.C. (1943) Thermodynamics of soil moisture, Hilgardia (California Agricultural Experiment Station), vol. 15, p. 31-298.

Eucken, A. A. (1948) Nachr. Ges. Akad. Wiss. Gottingen, Math. - physik. Klasse, 38 ; and B. (1946) Z. Electrochem., vol. 52, p. 255.

Eyring, H. and Marchi, R.P. (1963) Significant structure theory of liquids, Journal of Chemical Education, vol. 40, p. 562-572.

Frank, H.S. (1958) Covalency in the hydrogen bond and the properties of water and ice, Proceedings of Royal Society (London), vol. A247, p. 481-492.

(1963) Desalinization Research Conference, Proceedings, NAS-NRC Publication 942, p. 141-155, National Academy of Science, Wash., D.C.

and Quist, A.S. (1961) Pauling's model and the thermodynamic proper -

ties of water, Journal of Chemical Physics, vol. 34, p. 604-611.

and Wen, W. (1957) Structural aspects of ion-solvent interaction in aqueous solutions: A suggested picture of water structure, Discussions, Faraday Society, vol. 24, p. 133-140.

Graham, 3, (1964) Adsorbed water on clay, Review of Pure and Applied Chemistry, vol. 14, p. 81-90.

Gurney, R.W. (1953) Ionic processes in solution. New York: McGraw-Hill BookCo.

Hemwall, J. B. and Low, P.F. (1955) The hydrostatic repulsive force in clay swelling, Soil Science, vol. 82, p. 135-145.

Hendricks, S. B. and Jefferson, M.E. (1938) Structure of kaolin and talcpyrophyllite hydrates and their bearing on water sorption of clays, American Mineralogist, vol. 23, p, 863-875.

Hill, T. L. (1950) Statistical mechanics of adsorption IX. Adsorption thermodynamics and solution thermodynamics, Journal of Chemical Physics, vol. 18, p. 246-256.

Hiller, K.H. (1964) Pressure induced gel-sol transition in bentonite suspensions, Nature, vol. $201, p_{0} 1118-1119$. 


\section{LITERATURE CITED (Cont'd)}

Hoekstra, P. (1965) Conductance of frozen bentonite suspensions, Soil Science Society of America; Proceedings, vol. 29, p. 519.

and Chamberlain, E. (1964) Electroosmosis in frozen soil, Nature, vol. 203, p. 1406-1407.

and Miller, R. D. (1965) Movement of water in a film between glass and ice, USA CRREL Research Report 153.

Jeffrey, G.A. (1963) The geometrical approach to the structure of water and the clathrate hydrates, Desalinization Research Conference, Proceedings, NAS-NRC Publication 942, National Academy of Science, Washington, D. C.

Jhon, M.S.; Grosh, J.; Ree, T.; and Eyring, H. (1966) Significant structure theory applied to water and heavy water, Journal of Chemical Physics, vol. 44, p. 1465-1472.

Kamb, Barclay (1965) Structure of ice VI, Science, vol. 150, p. 205-209.

Kato, C. (1959) Differential thermal analysis of clay minerals between the temperatures of $0^{\circ}$ and $-195^{\circ} \mathrm{C}$, Journal of the Ceramics Association, Japan, vol. 67, p. 243-246.

Khakimov, Kh. R. (1957) Problems in the theory and practice of artificial freezing of soil, Academy of Science USSR, Moscow.

Kolaian, J. $\dot{H}$ and Low, P.F. (1960) Thermodynamic properties of water in suspensions of montmorillonite, Clays and Clay Minerals, 9th National Clay Conference, Purdue University. New York: Pergamon Press, vol. 9, p. $71-84$.

(1963) Calorimetric determination of unfrozen water in montmorillonite pastes, Soil Science, vol. 95, p. 376-383.

Konnova, O.S. (1961) Vliianie obmennykh kationov na kriogennuiu teksturu gornoi porody i strukturu segregatsionnogo. 1'da (Effect of exchange cations on the cryogenic texture of soils and the structure of segregated ice), Issledovaniia po fizike i mekhanike merzlykh gruntov, vol. 4, p. 53-80.

Kumai, M. (1957) Electron microscope study of snow crystal nuclei: II, Geofisica Pura E Applicata, Milano, vol. 36, p. 169-181.

and Francis, K.E. (1962) Nuclei in snow and ice crystals on the Greenland Ice Cap under natural and artificially stimulated conditions, Journal of the Atmospheric Sciences, vol. 19, no. 6, p. 474-481.

Lange, W. J. (1965) Properties of clay water systems under pressure, Unpublished Ph. D. Dissertation, University of Illinois; Dept. of Geology.

Litvan, G.G. (1963) The freezing of water and Xenon in porous vycor glass, $\mathrm{Ph}$. D. Dissertation, University of Toronto.

Lovell; C. W. (1957) Temperature effects on phase composition and strength of partially frozen soil, Highway Research Board Bulletin, no. 168, p. 74-95.

Low, P.F. (1961) Physical chemistry of clay-water interaction, Advances in Agronomy, vol. 13, p. 269-327.

Macey, $H . H_{0}$ (1942) Clay-water relationships and the internal mechanism of drying, Transactions of the British Ceramics Society, vol. 41, p. 73-121.

Marchi, R.P. and Eyring, H. (1964) Application of significant structure theory to water, Journal of Physical Chemistry, vol. 68, p. 221-228. 


\section{LITERATURE CITED (Cont'd)}

Martin, R. T. (1960) Adsorbed water on clay, Clays and Clay Minerals, 9th National Clay Conference, Purdue University. New York: Pergamon Press, vol. 9, p. 28-70.

Martynov, G.A. (1956) Okalorimetricheskoi metodike opredeleniia kolichestva nezamerzshei vody v merzlykh gruntov (Calorimetric method of determining the amount of unfrozen water within frozen ground), Materialy k osnovam ucheniia o merzlykh zonakh zemnoi kory; vol. III, p. 179-185. National Research Council of Canada, Ottawa, Technical Translation 1088.

(1959) Principles of geocryology. Part I: General geocryology. Chapter 6: Heat and moisture transfer in freezing and thawing soils, Akad Nauk SSSR, p. 153-192. National Research Council of Canada, Technical Translation 1065.

Mason, B.J. and Maybank, J. (1958) Ice-nucleating properties of some natural mineral dust, Quarterly Journal of the Royal Meteorological Society, vol. 42, p. 723-728.

Mathieson, A. Mcl. (1958) Magnesium vermiculite: A refinement and reexamination of the crystal structure of the 14.36 A phase, American Mineralogist, vol. 43, p. 216-217.

and Walker, G.F. (1954) Crystal structure of magnesiumvermiculite, American Mineralogist, vol. 39, p. 231-255.

Migal, P.K. and Russu (1965) Adsorption of organic vapors on charcoal and silica gel in the presence of added air, Vch. Zap. Tiraspolsk. Gas. Ped. Inst. No. 13, p. 136-142 (1964)(Russian). Cited in Chemical Abstracts, vol. 63, p. $17182 \mathrm{~b}$.

Miller, R.J. and Low, P.F. (1963) Threshold gradient for water flow in clay systems, Soil Science Society of America, Proceedings, vol. 27, p. 605-609.

Mooney, R. W.; Kennan, A. G. and Wood, L.A. (1952) Adsorption of water vapor by montmorillonite. I: Heat of desorption and application of BET theory, Journal of the American Chemical Society, vol. 74, p. 1367-1374.

Morgan, J. and Warren, B. E. (1938) X-ray analysis of the structure of water, Journal of Chemical Physics, vol. 6, p. 666-673.

Nemethy, G. and Schéraga, H. A. (1961) Structure of water and hydrophobic bonding in proteins I. A model for the thermodynamic properties of liquid water, Journal of Chemical Physics, vol. 36, p. 3382-3400.

Nersesova, Z.A. (1953) Kalorimetricheskii metod opredeleniiu l'distosti gruntov (The calorimetric method of determining the ice content of soils), Materialy po laboratornym issledovaniiam merzlykh gruntov, Sb-1, p. 77-85, Akad. Nauk SSSR.

(1954) Instruktivnye ukazaniia po opredeleniiu kolichestva nezamerzshei vody i l'da v merzlykh gruntakh (Measuring the amount of unfrozen water and ice in frozen soils). Materialy po laboratornym issledovaniiam merzlykh gruntov, Sb-2, Akad, Nauk SSSR.

and Tsytovich, N.A. (1963) Unfrozen water in frozen soils, Contributions by the Russian delegation to the International Conference on Permafrost, N. A. Tsytovich, ed., Published by Acad. of Science, USSR, Moscow, 1963. English Translation in Proceedings, First International Conference on Permafrost, National Academy of Sciences National Research Council, Publication no. 1287, p. 230-237. 


\section{LITERATURE CITED (Cont'd)}

Oster, J.D. and Low, P.F. (1964) Heat capacities of clay and clay-water mixtures, Soil Science Society of America, Proceedings, vol. 28, p. 605-609.

Pauling, L (1959) In Hydrogen bonding, D. Hadzi, Ed. London: Pergamon Press, p. 1 .

Rosenquist, I. Th. (1959) Physico - chemical properties of soils: Soil-water systems, Proceedings, American Society of Civil Engineers, Journal of the Soil Mechanics and Foundations Division, vol. 85 (SM2), p. 31-53.

Schaefer, V.J. (1958) The production of clouds containing supercooled water droplets or ice crystals under laboratory conditions, Bulletin of the American Meteorological Society, vol. 29, p. 175.

Telford; J.W. and Turner, J.S. (1963) The motion of wire through ice, Philosophical Magazine, vol. 8, p. 527.

Tsytovich, N.A. et al. (1959) Principles of geocryology. Part I: General geocryology. Chapter 5, Akad Nauk SSSR, p. 108-152. National Research Council of Canada, Technical Translation 1164.

Williams, P.J. (1963) Specific heats and unfrozen water content of frozen soils, Proceedings, First Canadian Conference on Permafrost, National Research Council of Canada, Technical Memorandum No. 76.

Wu, T.H. (1964) A nuclear magnetic resonance study of water in clay, Journal of Geophysical Research, vol. 69, p. 1083-1091.

Young, D.M. and Crowell, A.S. (1962) Physical adsorption of gases. London: Butterworth's Publishers.

Zimmerman, J.R. and Lasater, J.A. (1958) Nuclear magnetic relaxation studies of adsorbed water on silica gel III, Journal of Physical Chemistry, vol. 62, p. $1157-1163$. 
Unclassified

Security Classification

\section{DOCUMENT CONTROL DATA - R\&D}

(Security classification of titlo, body of abstract and indexing annotation must be entered when the overall report is classified) 1. ORIGINATIN G ACTIVITY (Corporate author)

U.S. Army Cold Regions Research and

Engineering Laboratory, Hanover, N.H.

\section{Unclassified}

3. REPORT TITLE

THE IN TERFACE BETWEEN ICE AND SILICATE SURFACES

4. DESCRIPTIVE NOTES (Type of report and inclusive dates)

Research Report 219

5. AUTHOR(S) (Last name, first name, initial)

Anderson, Duwayne M.

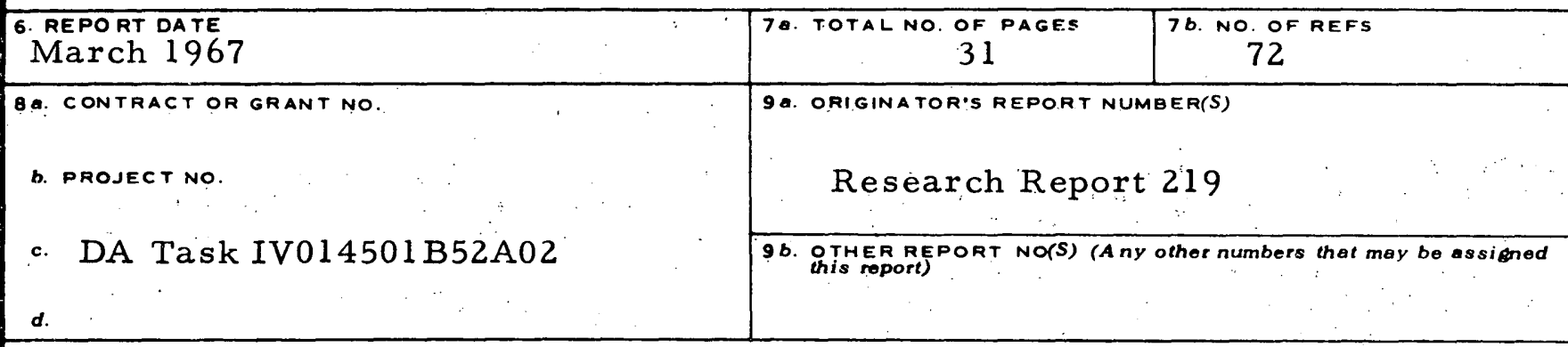

10. AVAILABILITY/LIMITATION NOTICES

Distribution of this document is unlimited.

11. SUPPL EMENTARY NOTES

Experiments have been conducted with a particular layer lattice silicate, montmorillonite, in order to study the interaction of water and ice with silicate surfaces.: The structural features of this class of silicate minerals are described, and other aspects which have a particular bearing on interfacial phenomena are discussed. Emphasis is placed on the nature of water and aqueous solutions, mechanisms of clay-water interaction, physical and thermodynamic properties of clay-adsorbed water, freezing point depression and supercooling, the existence of unfrozen interfacial. water, spatial distribution of unfrozen water, the nature of the ice phase, and phase relationships. 
Unclassified

Security Classification

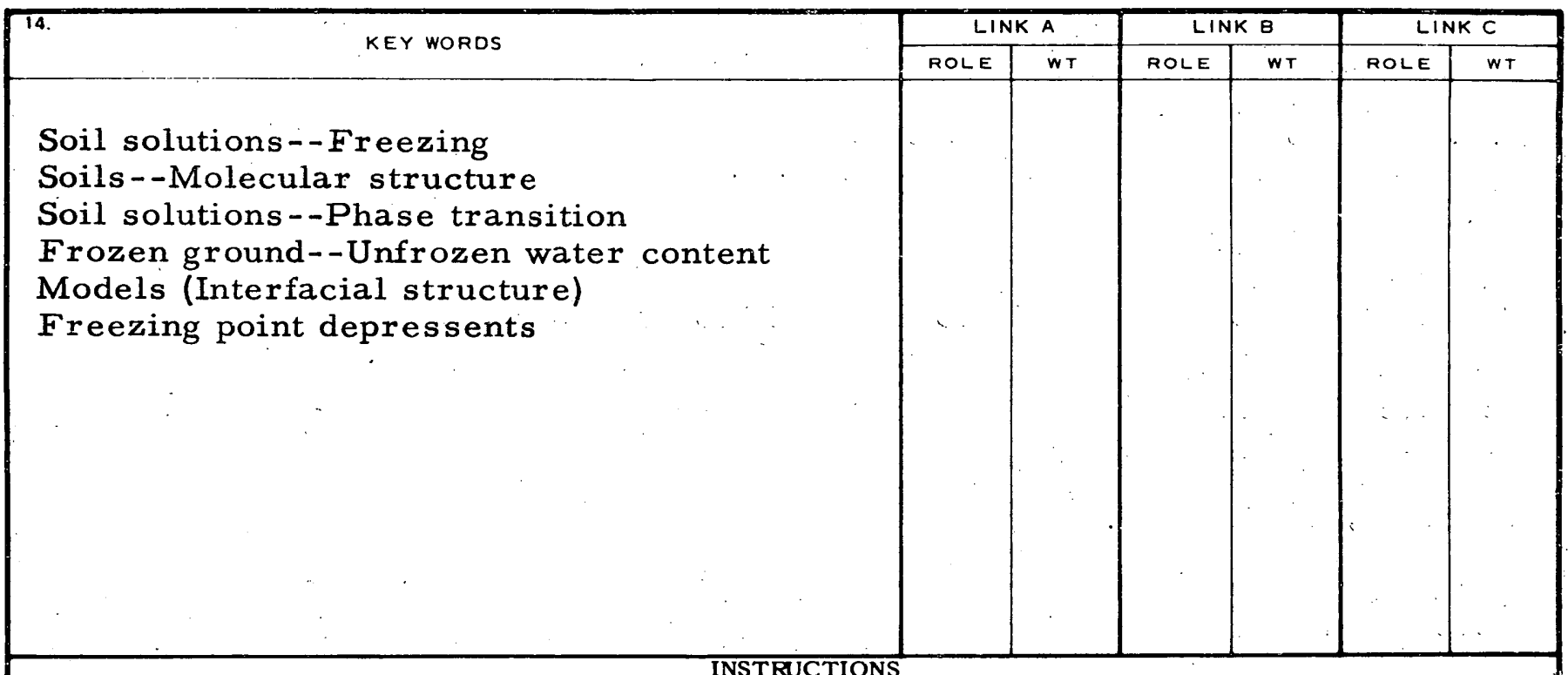

1. ORIGINATING ACTIVITY: Enter the name and address of the contractor, subcontractor, grantee, Department of Defense activity or other organization (comorate author) issuing the report.

2a. REPORT SECURTY CLASSIFICATION: Enter the overall security classification of the report. Indicate whether "Restricted Data" is included. Marking is to be in accordance with appropriate security regulations.

2b. GROUP: Automatic downgrading is specified in DoD Directive 5200.10 and Armed Forces Industrial Manual. Enter the group number. Also, when applicable, show that optional markings have been used for Group 3 and Group 4 as authorized.

3. REPORT TITLE: Enter the complete report title in all capital letters. Titles in all cases should be unclassified. If a meaningful title cannot be selected without classification, show title classification in all capitals in parenthesis immediately following the title.

4. DESCRIPTIVE NOTES: If appropriate, enter the type of report, e.g., interim, progress, summary, annual, or final. Give the inclusive dates when a specific reporting period is covered.

5. AUTHOR(S): Enter the name(s) of author(s) as shown on or in the report. Enter last name, first name, middle initial. If military, show rank and branch of service. The name of the principal author is an absolute minimum requirement.

6. REPORT DATE: Enter the date of the report as day, month, year; or month, year. If more than one date appears on the report, use date of publication.

7a. TOTAL NUMBER OF PAGES: The total page count should follow normal pagination procedures, i. e., enter the number of pages containing information.

7b. NUMBER OF REFERENCES: Enter the total number of references cited in the report.

8a. CONTRACT OR GRANT NUMBER: If appropriate, enter the applicable number of the contract or grant under which the report was written.

$8 b, 8 c, 8 d 8 d$. PROJECT NUMBER: Enter the appropriate military department identification, such as project number, subproject number, system numbers, task number, etc.

9a. ORIGINATOR'S REPORT NUMBER(S): Enter the official report number by which the document. will be identified and controlled by the originating activity. This number must be unique to this report.

9b. OTHER REPORT NUMBER(S): If the report has been assigned any other report numbers (either by the originator or by the sponsor), also enter this number(s).
10. AVAILABILITY/LIMITATION NOTICES: Enter any limitations on further dissemination of the report, other than those imposed by security classification, using standard statements such as:

(1) "Qualified requesters may obtain copies of this report from DDC."

(2) "Foreign announcement and dissemination of this report by DDC is not authorized."

(3) "U. S. Government agencies may obtain copies of this report directly from DDC. Other qualified DDC users shall request through

(4) "U. S. military agencies may obtain copies of this report directly from DDC. Other qualified users shall request through

(5) "All distribution of this report is controlled Qual. ified DDC users shall request through ."

If the report has been furnished to the Office of Technical Services, Department of Commerce, for sale to the public, indicate this fact and enter the price, if known.

11. SUPPLEMENTARY NOTES: Use for additional explanatory notes.

12. SPONSORING MILITARY ACTIVITY: Enter the name of the departmental project office or laboratory sponsoring (pay ing for) the research and development. Include address.

13. ABSTRACT: Enter an abstract giving a brief and factual summary of the document indicative of the report, even though it may also appear elsewhere in the body of the technical report. If additional space is required, a continuation sheet shall be attached.

It is highly desirable that the abstract of classified reports be unclassified. Each paragraph of the abstract shall end with an indication of the military security classification of the information in the paragraph, represented as (TS), (S), (C), or (U).

There is no limitation on the length of the abstract. However, the suggested length is from 150 to 225 words.

14. KEY WORDS: Key words are technically meaningful terms or short phrases that characterize a report and may be used as index entries for cataloging the report. Key words must be index entries for cataloging the report. Key is required. Idenfiers, such as equipment model designation, trade name, military project code name, geopraphic location, may be used as key words but will be followed by an indication of technical. context. The assignment of links, rules, and weights is optional. 